\title{
WIVERN: A new satellite concept to provide global in-cloud winds, precipitation and cloud properties.
}

Article

Published Version

Creative Commons: Attribution 4.0 (CC-BY)

Open Access

Illingworth, A. J., Battaglia, A., Bradford, J., Forsythe, M., Joe, P., Kollias, P., Lean, K., Lori, M., Mahfouf, J.-F., Mello, S., Midthassel, R., Munro, Y., Nicol, J., Potthast, R., Rennie, M., Stein, T. H. M., Tanelli, S., Tridon, F., Walden, C. J. and Wolde, M. (2018) WIVERN: A new satellite concept to provide global in-cloud winds, precipitation and cloud properties. Bulletin of the American Meteorological Society, 99 (8). pp. 1669-1687. ISSN 1520-0477 doi: https://doi.org/10.1175/bams-d-160047.1 Available at https://centaur.reading.ac.uk/75580/

It is advisable to refer to the publisher's version if you intend to cite from the work. See Guidance on citing.

To link to this article DOI: http://dx.doi.org/10.1175/bams-d-16-0047.1

Publisher: American Meteorological Society

All outputs in CentAUR are protected by Intellectual Property Rights law, including copyright law. Copyright and IPR is retained by the creators or other copyright holders. Terms and conditions for use of this material are defined in the End User Agreement. 


\section{www.reading.ac.uk/centaur}

\section{CentAUR}

Central Archive at the University of Reading

Reading's research outputs online 


\title{
WIVERN \\ A New Satellite Concept to Provide Global In-Cloud Winds, Precipitation, and Cloud Properties
}

\author{
A. J. lllingworth, A. Battaglia, J. Bradford, M. Forsythe, P. Joe, P. Kollias, K. Lean, \\ M. Lori, J.-F. Mahfouf, S. Melo, R Midthassel, Y. Munro, J. Nicol, R. Potthast, \\ M. Rennie, T. H. M. Stein, S. Tanell, F. Tridon, C. J. Walden, and M. Wolde
}

A new satellite concept with a conically scanning W-band Doppler radar to provide in-cloud winds, together with estimates of global rainfall, snowfall, and cloud properties, is examined.

A ccording to the World Meteorological Organization (WMO), windstorms are by far the largest contributor to economic losses caused by weather-related hazards, resulting in approximately $\$ 500$ billion (U.S. dollars, adjusted to 2011) of damage over the last decade globally (Zhang 2016). With more than $50 \%$ of the Earth's population concentrated in coastal developments and megacities, extreme weather events have an increasing potential to cause significant and recurring damage in terms of both loss of life and economic loss. As such, disaster risk reduction has been singled out by the WMO as their number one strategic priority, highlighting the importance of improving the accuracy and effectiveness of forecasts and early warnings of high-impact meteorological environmental hazards (Zhang 2016). Baker et al. (2014) provide an excellent review of the need for global wind measurements and argue that the measurement of the threedimensional global wind field is the final frontier that must be crossed to significantly improve the initial conditions for numerical weather forecasts,
AFFILIATIONS: ILLINGWORTH, NiCOL, AND STEIN-Department of Meteorology, University of Reading, Reading, United Kingdom; BATTAGLIA AND TRIDON-University of Leicester, and National Centre for Earth Observation, Leicester, United Kingdom; BRADFORD AND WALDEN-Science and Technology Facilities Council, Chilton, United Kingdom; ForsYTHE-Met Office, Exeter, United Kingdom; JOE AND Melo-Environment and Climate Change Canada, Toronto, Ontario, Canada; KoluIAS-Stony Brook University, State University of New York, Stony Brook, New York; LeAN AND ReNNIE-European Centre for Medium-Range Weather Forecasts, Reading, United Kingdom; LORI-HPS-GmbH, Munich, Germany; MaHFOUF-Météo-France, Toulouse, France; MIDTHASSEL-European Space Agency, European Space Research and Technology Centre, Noordwijk, Netherlands; MunRo-Airbus Defence and Space Limited, Portsmouth, United
Kingdom; PотTHAST-Department of Meteorology, University of Reading, Reading, United Kingdom, and Deutscher Wetterdienst, Offenbach am Main, Germany; TANELLI-Jet Propulsion Laboratory, California Institute of Technology, Pasadena, California; WOLDENational Research Council, Ottawa, Ontario, Canada CORRESPONDING AUTHOR: Anthony J. Illingworth, a.j.illingworth@reading.ac.uk

The abstract for this article can be found in this issue, following the table of contents.

DOI:10.1175/BAMS-D-16-0047.I

In final form 16 December 2017 (0)2018 American Meteorological Society

(c) (i) This article is licensed under a Creative Commons Attribution 4.0 license. 
and quote $\mathrm{WMO}$ as determining that global wind profiles are "essential for operational weather forecasting on all scales and at all latitudes." Assimilation of additional wind observations from the $94-\mathrm{GHz}$ radar on the proposed future Wind Velocity Radar Nephoscope (WIVERN) satellite into weather forecast models should significantly improve weather prediction skill, allowing better focus of mitigation activities with respect to timing, location, and assignment of resources.

Particularly striking examples of the advantages of mitigation activities are Tropical Storm Nargis that hit Myanmar in 2008, when no preventive action was taken and 138,000 died, and the subsequent more powerful storm "Phaillin" that struck the east coast of India in October 2013 but caused only 43 fatalities because timely warnings were issued and a mass evacuation of those living in the coastal regions was organized. In Europe, the windstorms in 1999 were estimated to have caused EUR 18.5 billion of damage, and in 2009 on 24 January the very deep depression "Klaus" caused 28 deaths through drowning as it crossed the coast of western France leaving 1.7 million people without electricity. A succession of rapidly deepening depressions forming over the western Atlantic crossed the United Kingdom during December 2015-January 2016 with heavy rain and flooding resulting in insurance losses of about EUR 1.5 billion.

\begin{tabular}{|lcc|}
\hline \multicolumn{3}{|l}{ TABLE 2. A possible WIVERN radar configuration. } \\
\hline Parameter & Value & Unit \\
\hline Operating frequency & 94 & $\mathrm{GHz}$ \\
\hline Pulse repetition frequency & $\approx 4$ & $\mathrm{kHz}$ \\
\hline Pulse width & 3.3 & $\mu \mathrm{s}$ \\
\hline Range resolution & 500 & $\mathrm{~m}$ \\
\hline Antenna diameter & $1.8 \times 2.9$ & $\mathrm{~m} \times \mathrm{m}$ \\
\hline Antenna scan rate & 8 & $\mathrm{rpm}$ \\
\hline Off-zenith surface angle & 41.4 & $\circ$ \\
\hline Orbit height & 500 & $\mathrm{~km}$ \\
\hline Slant range & 650 & $\mathrm{~km}$ \\
\hline Height resolution & 800 & $\mathrm{~m}$ \\
\hline H-V pulse separation & 20 & $\mu \mathrm{s}$ \\
\hline Folding velocity & 40 & $\mathrm{~m} \mathrm{~s}^{-1}$ \\
\hline $\begin{array}{l}\text { Doppler accuracy } \\
\text { (20-km integration, } Z>-20 \mathrm{dBZ} \text { ) }\end{array}$ & 2 & $\mathrm{~m} \mathrm{~s}^{-1}$ \\
\hline
\end{tabular}

WMO has outlined the systematic observation requirements for satellite-based products (GCOS 2006) as part of their rolling requirements review process and also maintains requirements in the Observing Systems Capabilities Analysis and Review tool (OSCAR 2016). The relevant numerical weather prediction (NWP) requirements for winds are summarized in Table 1. One conically scanning WIVERN radar placed in low-Earth orbit could measure the line-of-sight (LOS) component of the horizontal wind and should be able to satisfy the breakthrough requirements in Table 1 for in-cloud winds, except for the 6-h observing cycle that would require multiple satellites. To achieve the observation requirements of having a fine vertical resolution and a short observing cycle, we currently envisage (Table 2) a 94- $\mathrm{GHz}$ (3.2-mm wavelength) radar with a $2.9 \mathrm{~m} \times 1.8 \mathrm{~m}$ elliptical antenna producing a narrow, conically scanning pencil beam at $38^{\circ}$ off nadir and $41^{\circ}$ off zenith at the surface with an orbit altitude of $500 \mathrm{~km}$ and a surface footprint of approximately $1 \mathrm{~km}$ in diameter. These parameters are chosen as a compromise between the need to have a higher orbit and thus a broader ground track to reduce the satellite revisit time, and the consequent requirement of a much larger antenna to maintain the $1-\mathrm{km}$ vertical resolution when the slant path to the surface is increased. The 2.9-m elliptical antenna would have a beamwidth of $0.11^{\circ}$ in the horizontal and $0.08^{\circ}$ in the vertical, so, in combination with a $3.3-\mu$ s pulse length $(500-\mathrm{m}$ roundtrip slant path), the vertical resolution $(-3 \mathrm{~dB})$ would be about $800 \mathrm{~m}$ assuming both the antenna beam pattern and pulse shape are Gaussian. The preferred frequency is $94 \mathrm{GHz}$, as a $35-\mathrm{GHz}$ radar would have a pencil beam 2.7 times wider with consequent loss of vertical resolution. As indicated by the sketch in Fig. 1, the antenna would rotate once every $7.5 \mathrm{~s}$ tracing out a circular ground track $800 \mathrm{~km}$ in diameter advancing $50 \mathrm{~km}$ for each revolution.

The WIVERN mission would be complementary to other observing systems providing unique insights into the structure of winds within clouds and precipitating systems. The impact on NWP is expected to be on features in the models that are long lasting when 


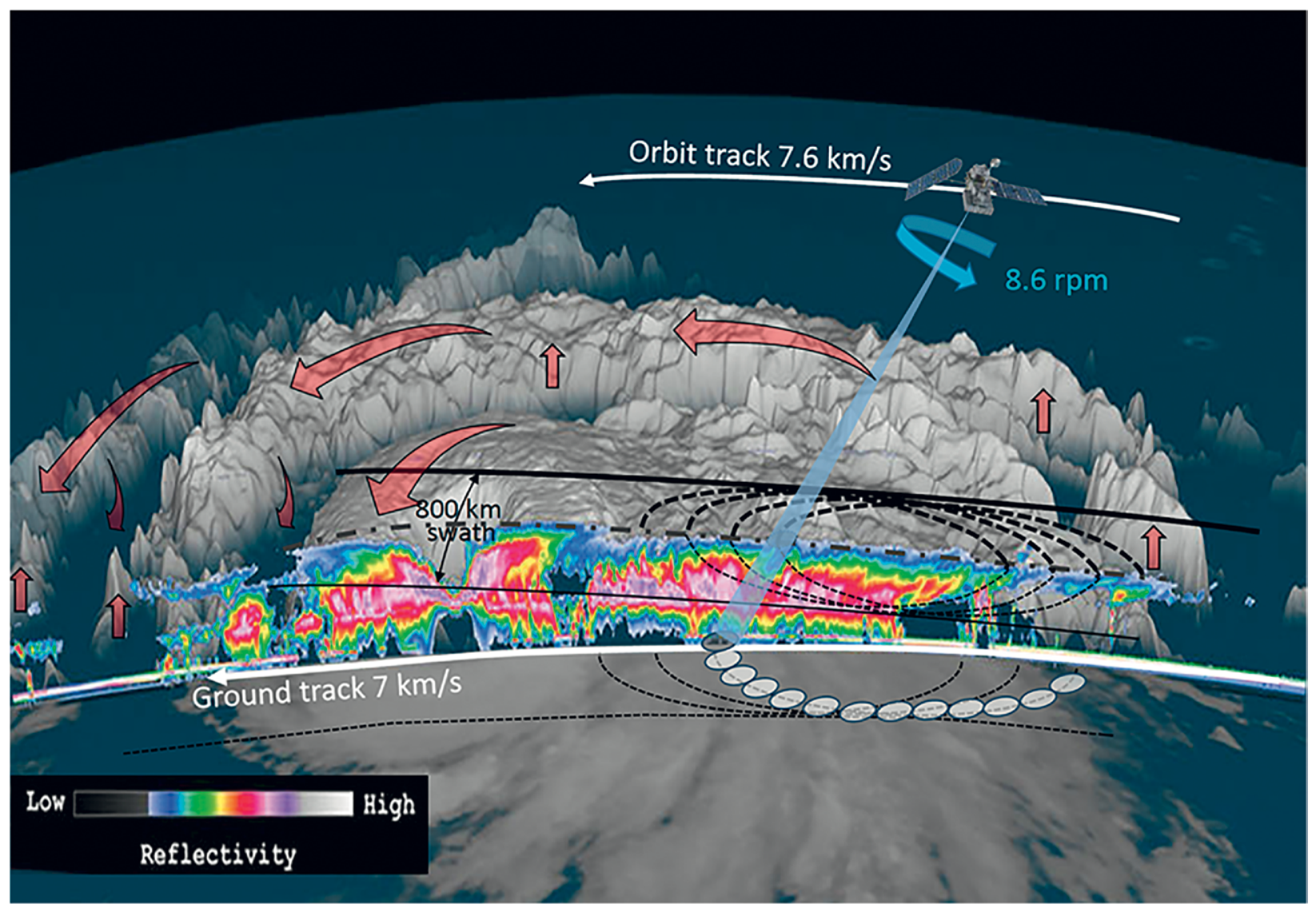

FIG. I. The WIVERN concept. The dashed black lines correspond to the scanning ground track. For every 7.5-s revolution the satellite advances $50 \mathrm{~km}$. The red arrows are indicative of the wind circulation. The background image [credit: Japan Aerospace Exploration Agency (JAXA)-National Aeronautics and Space Administration (NASA)-Colorado State University; N. D. Tourville] corresponds to an overpass of CloudSat over Supertyphoon Atsani at 0327 UTC 19 Aug 2015.

compared to the revisit times, so it would be necessary to identify convective motions that are not representative of the large-scale flow. The Aeolus Doppler wind lidar satellite mission (Stoffelen et al. 2005) is expected to measure line-of-sight winds in clear air, through optically thin clouds/aerosol and from the top of optically thick clouds/aerosol, but it lacks the penetrating capability of a radar for measuring within most clouds. To improve NWP forecasts, the need is for wind observations upstream of the areas were the wind damage may occur 24-48 h later; McNally (2002) has shown that these "meteorologically sensitive areas" are often cloudy. Figure 2 shows the coverage expected in one day for the notional WIVERN configuration of a $500-\mathrm{km}$ orbit tracing out an $800-\mathrm{km}$-diameter ground track that results in a revisit time of about once a day for latitudes poleward of $50^{\circ}$ and more frequent visits over the polar regions. These regions have become an important area for climate and weather studies as demonstrated by the recently launched WMO Polar Prediction Project that aims to promote cooperative international research enabling the development of improved weather and environmental prediction services for the polar regions. In the Arctic the fast warming, the decrease in ice cover, and the recent opening of the Northwest Passage have attracted attention. The limited number of ground-based profiling observations in the Arctic regions indicate the ubiquitous presence of light precipitation often limited to the lowest $4 \mathrm{~km}$ whose properties may be sensitive to the local and midlatitude aerosol transported from the midlatitudes. WIVERN observations would provide pan-Arctic coverage and reveal the true physical and dynamic characteristics of the clouds and precipitation in these data-sparse regions.

\section{THE WIVERN CONCEPT AND PREDICTED} DOPPLER PERFORMANCE. WIVERN would utilize a $94-\mathrm{GHz}$ transmitter similar to the one that has been operating beyond expectations on the nadirpointing CloudSat Cloud Profiling Radar (Stephens et al. 2008; Tanelli et al. 2008) since its launch in 2006. 


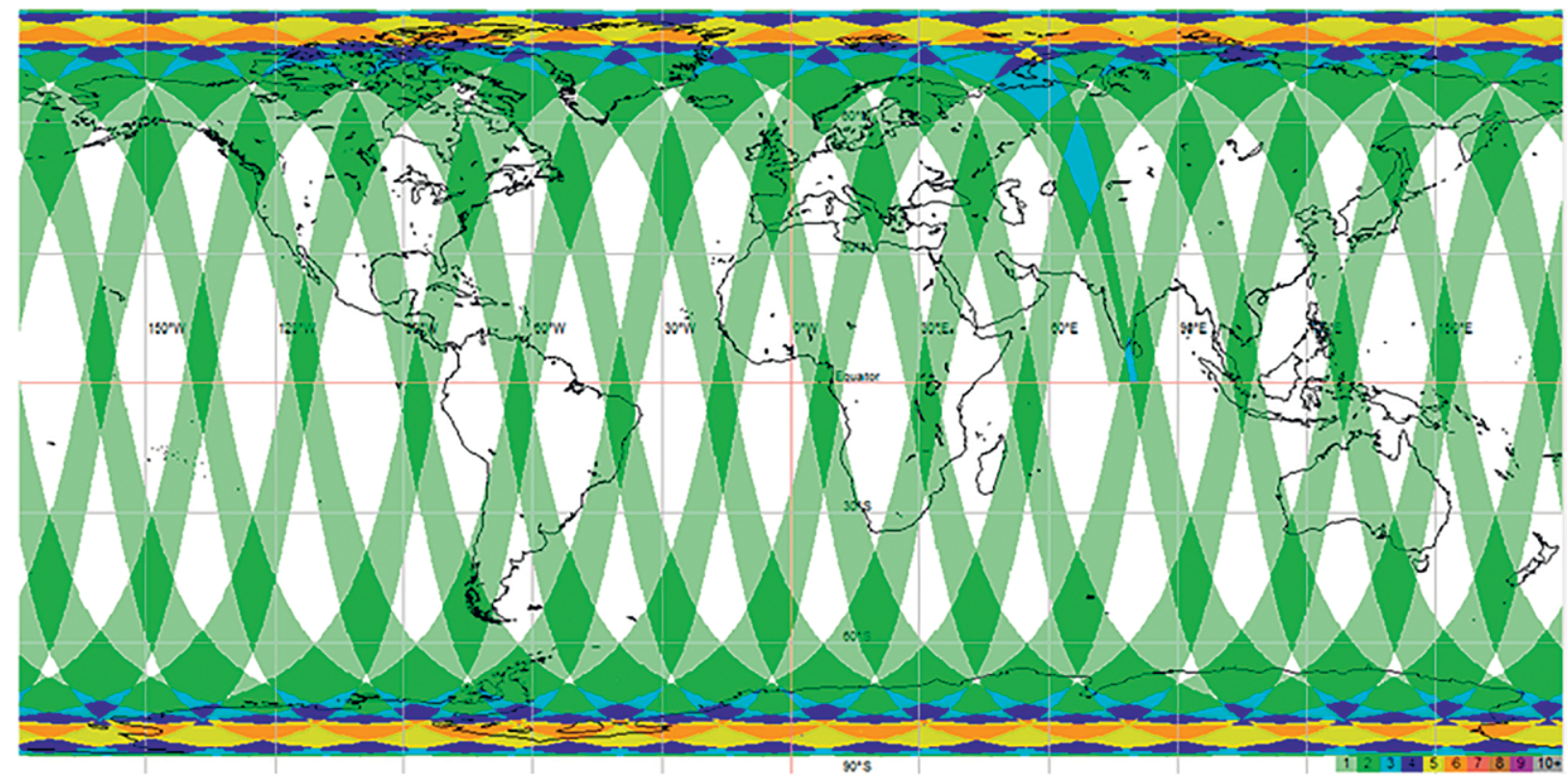

FIG. 2. Daily coverage for a possible WIVERN 500-km orbit with $800-\mathrm{km}$-wide ground track and $65 \mathrm{I}-\mathrm{km}$ slant path. Light green indicates one visit per day, dark green shows two, and blue is for three.

CloudSat transmits 3.3- $\mu$ s $(500 \mathrm{~m})$ pulses at a pulse repetition frequency (PRF) of approximately $4 \mathrm{kHz}$ with 1,800 -W peak power (at beginning of life) and $24-\mathrm{W}$ mean radiated power. By integrating the pulses for 0.16 $\mathrm{s}$, equivalent to a distance of $1.09 \mathrm{~km}$ along track, during which about 600 pulses are transmitted, it was therefore possible during CloudSat's prime mission to detect targets with reflectivities above $-30 \mathrm{dBZ}$ and a single pulse signal-to-noise ratio (SNR) of $0 \mathrm{~dB}$ for an echo of $\approx-16 \mathrm{dBZ}$. The proven performance of CloudSat can be used both to estimate the accuracy of the retrieved LOS speeds from WIVERN, and the climatology of radar reflectivity profiles around the globe from several years of CloudSat data can be used to predict the number of occasions when WIVERN would observe accurate winds. An improvement in the sensitivity of WIVERN compared to CloudSat can be expected, because of the shorter slant path to the ground $(\approx 650 \mathrm{~km}$ vs CloudSat's $\approx 710 \mathrm{~km})$ and the larger antenna $(1.8 \mathrm{~m} \times 2.9 \mathrm{~m}$ for WIVERN vs CloudSat's circular $1.85 \mathrm{~m}$ ). This should lead to a single-pulse SNR of $0 \mathrm{~dB}$ for a return of $\approx-19 \mathrm{dBZ}$, and for integration lengths of 1,5 , and $10 \mathrm{~km}$ the reflectivity thresholds for $0-\mathrm{dB}$ SNR will be $-24,-27.5$, and $-30.5 \mathrm{~dB} Z$, respectively.

The Earth Cloud Aerosol and Radiation Explorer (EarthCARE) satellite (Illingworth et al. 2015) will use the conventional pulse-pair technique to detect the nadir Doppler velocity of the hydrometeors, using a PRF of $7.5 \mathrm{kHz}$, so that only one pulse at a time is present in the troposphere, but this leads to a folding velocity of just $6 \mathrm{~m} \mathrm{~s}^{-1}$ and a noisy Doppler estimate because of the low correlation of the phases of the pulse-pair echoes. As explained in the "Why polarization diversity?" sidebar, WIVERN overcomes this dilemma by estimating the Doppler velocity using the polarization-diversity pulse-pair (PDPP) technique (Pazmany et al. 1999) and would transmit a pair of pulses: one with horizontal polarization $(\mathrm{H})$ and the other with vertical $(\mathrm{V})$, with a short separation, $T_{\mathrm{hv}}$. A value of $20 \mu \mathrm{s}$ is proposed for $T_{\mathrm{hv}}$ so that the folding velocity is $40 \mathrm{~m} \mathrm{~s}^{-1}$ and large enough to comfortably exceed the errors of the winds calculated in the NWP models. The pulse separation would be $3 \mathrm{~km}$ along the slant path or $2.3 \mathrm{~km}$ in the vertical.

WIVERN would trace out a quasi-circular ground track of diameter $800 \mathrm{~km}$ on the ground, advancing $50 \mathrm{~km}$ along track for each rotation with the footprint traveling at $335 \mathrm{~km} \mathrm{~s}^{-1}$ or $1 \mathrm{~km}$ in $3 \mathrm{~ms}$. If it were to use the same $4-\mathrm{kHz}$ PRF as CloudSat, in each kilometer it could transmit $10 \mathrm{H}-\mathrm{V}$ pulse pairs each with a $20-\mu$ s separation to measure Doppler, interleaved with two single $\mathrm{H}$ or $\mathrm{V}$ pulses to measure the LDR of the targets to flag any potential problems of cross talk between the two polarizations. The 10 pulse pairs would alternate between $\mathrm{H}-\mathrm{V}$ and $\mathrm{V}-\mathrm{H}$ to distinguish between phase shifts due to Doppler and to differential phase shift on backscatter (Pazmany et al. 1999). The predicted Doppler accuracies for 1-, 5-, and $20-\mathrm{km}$ integrations are displayed in Fig. 3. The measured line-of-sight component (LOS) of the wind can be converted to the horizontal line-of-sight (HLOS) winds if the vertical wind component is 


\section{WHY POLARIZATION DIVERSITY?}

The simple answer to the question "why polarization diversity" is that at $94 \mathrm{GHz}$ we need to have two pulses that are very close together because the motion of the satellite combined with the finite beamwidth of the radar results in a rapid decorrelation of the phases of the return signals. If the pulses are close together, they would both be in the cloud at the same time: to distinguish them, WIVERN transmits pairs of pulses with alternating polarization-H (red) and $\mathrm{V}$ (blue) - spaced by a short time separation, $T_{h v}$, and receives the return signals in both polarizations (Fig. SBIa). Because of the orthogonality of the polarizations, the horizontally and vertically polarized pulses are transmitted and backscattered, and then propagate through the atmosphere independently so that the returns from the two closely spaced pulses can be separated. Crosspolar interferences are typically weak and WIVERN signal processing includes ways for removing their effects.

In Fig. SBIc, the red $\mathrm{H}$ pulse is at height $h$, and at a short time later (e.g., $T_{\text {hv }}=20 \mu \mathrm{s}$ ), the blue $V$ pulse has moved (e.g., $3 \mathrm{~km}$ ) along the slant path and is at height $h$ (Fig. SBId). The estimation of the Doppler velocity is based on the phase change between the backscattered signals of these two pulses. Figure SBIb (green-shaded region) shows that for a $T_{\text {hv }}$ of only $20 \mu$ s the targets have not had time to reshuffle, so the phases remain correlated and can be measured accurately. The maximum unambiguous phase shift value of $\pm 180^{\circ}$ is reached when the cloud particle targets move one-quarter of a wavelength ( $800 \mu \mathrm{m}$ at $\mathrm{W}$ band), equivalent, with $T_{\text {hv }}=20 \mu \mathrm{s}$, to a folding velocity of $\pm 40 \mathrm{~m} \mathrm{~s}^{-1}$ (top $x$ axis in Fig. SBIb).

Contrast this with the situation encountered in a conventional pulse pair (Fig. SBle) when the phase change is derived between two pulses with the same polarization, with the second red $\mathrm{H}$ pulse trailing $130 \mu \mathrm{s}(\approx 20 \mathrm{~km})$ behind the first so that only one pulse at a time is in the troposphere. Because of the fast movement of the satellite, the targets would appear to have been almost completely reshuffled (redshaded region in Fig. SBIb), the phase difference would be very noisy, and the maximum "folding" velocity only about $6 \mathrm{~m} \mathrm{~s}^{-1}$, far below that required for retrieving line-of-sight winds.
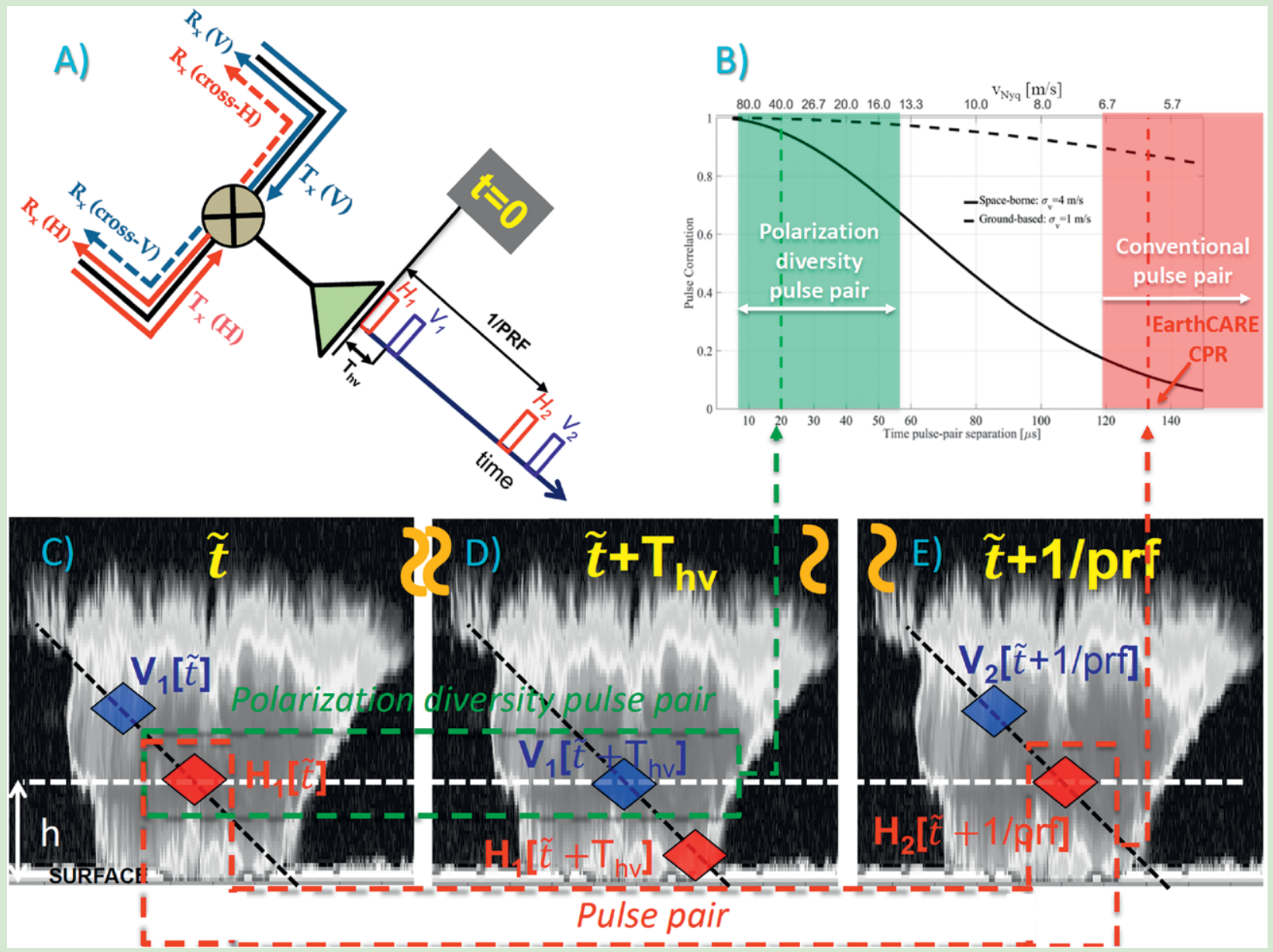

FIG. SBI. A high Doppler folding velocity is needed to measure atmospheric winds. At $94 \mathrm{GHz}$, this is achieved be transmitting two closely spaced pulses, one with horizontal polarization and the other vertical. 


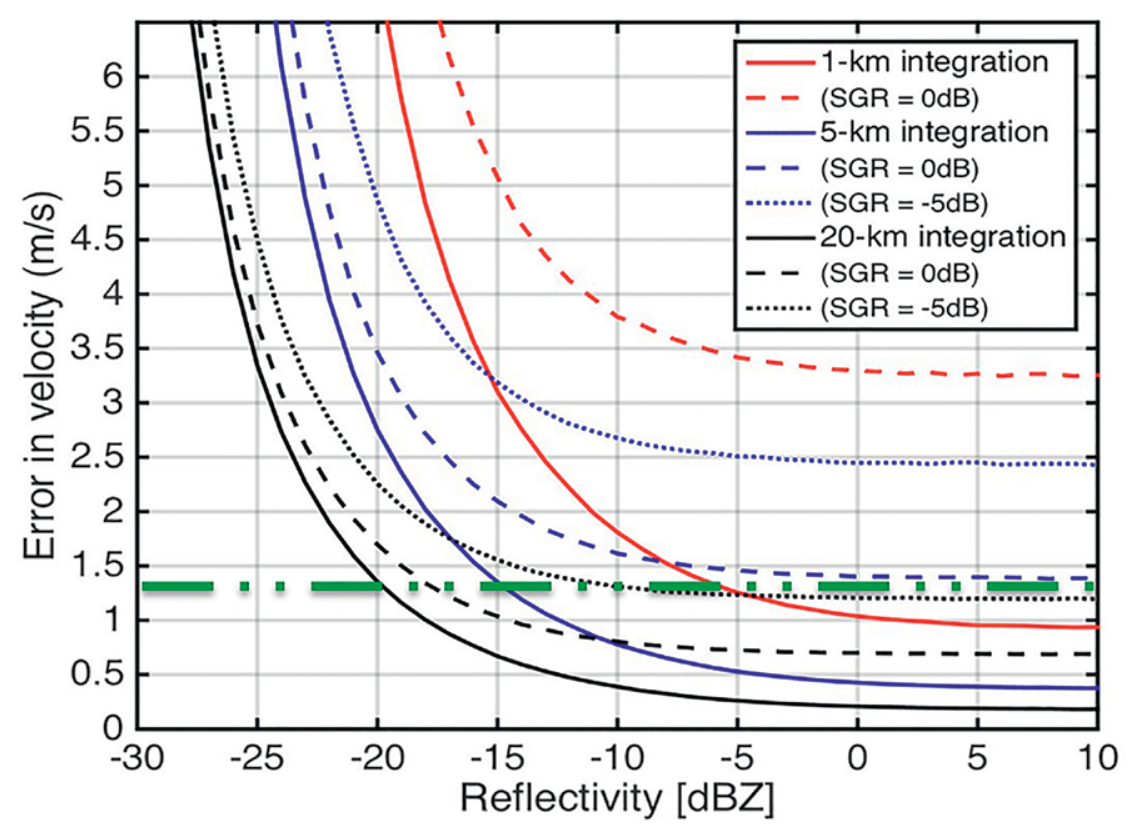

FIG. 3. Theoretical random error in the LOS-retrieved Doppler velocity for WIVERN as a function of target reflectivity for a $20-\mu \mathrm{s} \mathrm{H}-\mathrm{V}$ pulse separation and a $3.5 \mathrm{~m} \mathrm{~s}^{-1}$ Doppler width due to satellite motion. Single-pulse SNR of $0 \mathrm{~dB}$ is found for a -19-dBZ target. Colored solid lines show the following: red, I-km integration ( 10 pulse pairs); blue, $5 \mathrm{~km}$ (50 pulse pairs); black, $20 \mathrm{~km}$ (200 pulse pairs) and SGR $=\infty$. Dashed lines show SGR $=0 \mathrm{~dB}$. Dotted lines show $S G R=-5 \mathrm{~dB}$.

assumed to be zero. To satisfy the WMO requirement of a horizontal wind component (HLOS) of $2 \mathrm{~m} \mathrm{~s}^{-1}$, an LOS wind accuracy of $1.35 \mathrm{~m} \mathrm{~s}^{-1}$ is needed (green dashed line in Fig. 3). This can be achieved for $20-\mathrm{km}$ integration if the echoes are $>-20 \mathrm{~dB} Z$, and for $5 \mathrm{~km}$ they should be above $-15 \mathrm{dBZ}$, provided there are no "ghosts" caused by cross talk between the $\mathrm{H}$ and $\mathrm{V}$ returns. Note that factors such as beam-pointing knowledge and nonuniform beam filling (discussed later) may well prevent the theoretical accuracies $<0.5 \mathrm{~m} \mathrm{~s}^{-1}$ being achieved for the higher $\mathrm{dB} Z$ values.

To gauge the number of sufficiently accurate wind observations expected from the proposed WIVERN satellite and their susceptibility to ghosts, an analysis of reflectivity profiles averaged over a 20-km along-track integration for four years of CloudSat data is displayed in Fig. 4. The top panel in Fig. 4 shows that, averaged over the tropics and northern midlatitudes, clouds with echoes $>-20 \mathrm{dBZ}$ are present for about $10 \%$ of the time between heights of 1 and $10 \mathrm{~km}$, and this fraction does not change markedly for reflectivity thresholds of $-25,-20$, and $-15 \mathrm{dBZ}$. These figures are for $20-\mathrm{km}$ integration but change by less than $0.2 \%$ for shorter integrations down to $1 \mathrm{~km}$. For clouds $10 \mathrm{~km}$ deep, the sloping WIVERN sample at cloud top will be displaced by $7 \mathrm{~km}$ horizontally compared to the ground footprint, the insensitivity of the CloudSat statistics to the integration length suggests that this horizontal displacement and areas of broken cloud will not bias the WIVERN observations. The vertical resolution of the WIVERN winds should be better than $1 \mathrm{~km}$; so, for a 20 $\mathrm{km}$ integration and before thinning, an average of one wind with an accuracy better than $2 \mathrm{~m} \mathrm{~s}^{-1}$ (HLOS) should be detected every $60 \mathrm{~ms}$ or 1.4 million day ${ }^{-1}$.

Ghost echoes caused by cross talk between the $\mathrm{H}$ and $\mathrm{V}$ returns may occur when there are high-reflectivity depolarizing targets $2 \mathrm{~km}$ above or below much weaker targets. The phases of the ghost echo are uncorrelated with the true return signal so their effect will be to increase the random error in the velocity estimate at each gate; this may occur over several neighboring gates but these random errors should not introduce any bias as the ghost echoes decorrelate between successive pulse pairs. The bottom panel in Fig. 4 is a plot of CloudSat observations for each height level $h$ of the fraction of the time that there is a denser cloud with a reflectivity $20 \mathrm{~dB}$ greater at a height either $2 \mathrm{~km}$ above or below $h$. For clouds with reflectivities above $-15 \mathrm{dBZ}$ this occurs about $2 \%$ of the time. As a worst case, we assume that the LDR of the denser clouds is $-15 \mathrm{~dB}$, then on $2 \%$ of occasions there would be a signal-to-ghost ratio (SGR) of $-5 \mathrm{~dB}$; Fig. 3 shows that the LOS velocity accuracy of $1.35 \mathrm{~m} \mathrm{~s}^{-1}$ could still be achieved for $20-\mathrm{km}$ integration for $\mathrm{dBZ}>-10 \mathrm{dBZ}$. We conclude that significant ghost echoes from hydrometeor returns should be rare. In the next section we will present some observations to support this conclusion. We will also consider the more serious problem of ghost echoes and biases in the velocity estimates in gates close to the surface as a result of surface clutter, and the biases due to both the vertical wind shear and by the satellite motion when there is nonuniform beam filling.

If the winds from WIVERN are to be assimilated, it will be necessary to identify regions where LOS winds are affected by convection and are not a representative 
component of the large-scale horizontal wind. Anderson et al. (2005) have analyzed aircraft observations of tropical convection and define an updraft core as a region of diameter $>500 \mathrm{~m}$ having a vertical velocity $>1 \mathrm{~m} \mathrm{~s}^{-1}$ and find that $90 \%$ of such cores have diameters of less than $3 \mathrm{~km}$. One year's continuous observations of profiles of vertical velocity and reflectivity made with the zenith-pointing $35-\mathrm{GHz}$ cloud radar at Chilbolton, United Kingdom, confirm that regions of up- and downdrafts exceeding $1 \mathrm{~m} \mathrm{~s}^{-1}$ are absent in stratiform clouds and are confined to convective regions where the reflectivity values exceed $+10 \mathrm{dBZ}$. From Fig. 3 we conclude that the LOS velocity should be accurate to $1.35 \mathrm{~m} \mathrm{~s}^{-1}$ for each kilometer along the ground track provided $Z$ is above $-5 \mathrm{dBZ}$. We propose that convective regions should be identified by significant changes in LOS velocities on the kilometer scale and flagged as nonrepresentative for global NWP data assimilation users. These fluctuations of the observed LOS velocities should be of interest to those studying the characteristics and statistical properties of convective processes and for validating cloud-resolving models. The detailed evolution of individual convective clouds cannot be observed from a single satellite in low-Earth orbit so such studies are best conducted from aircraft.

The Global Climate Observing System (GCOS) has recently recommended (GCOS 2017) a satellite be launched to continue the dataset that CloudSat has been gathering on cloud reflectivity profiles since its launch in 2006 and to be continued by EarthCARE. WIVERN should be able to provide such data. Miller and Stephens (2001) show that a minimum detectable signal of $-28 \mathrm{dBZ}$ should detect a fraction of the true cloud field sufficient to reconstruct the instantaneous top of the atmosphere to within Clouds of the Earth's Radiant Energy System (CERES) requirements. WIVERN should achieve -27.5- $\mathrm{dBZ}$ sensitivity for 5-km along-groundtrack integration (50 pulse pairs) corresponding to 15-ms integration time, whereas CloudSat and EarthCARE will have a 5-km-nadir along-track reflectivity sample about every $0.8 \mathrm{~s}$, suggesting that WIVERN would obtain about a 50 -fold increase of IWC profiles.

The hydrometeor cloud targets are not perfect tracers of the wind, so a correction would be needed to account for their terminal velocity. Battaglia and Kollias (2015b) reported that the error in the mean terminal velocity of ice clouds is a function of their reflectivity and is $<0.2 \mathrm{~m} \mathrm{~s}^{-1}$ up to $10 \mathrm{dBZ}$ and that the random error for $Z<-5 \mathrm{~dB} Z$ is $0.5 \mathrm{~m} \mathrm{~s}^{-1}$; this should introduce a random error of $<1 \mathrm{~m} \mathrm{~s}^{-1}$ into the inferred horizontal component of the wind. For rainfall at $94 \mathrm{GHz}$, Mie scattering by the larger raindrops leads to a Doppler velocity of about $4 \pm 1 \mathrm{~m} \mathrm{~s}^{-1}$ (Lhermitte 1990), so a correction accurate to $<1 \mathrm{~m} \mathrm{~s}^{-1}$ of the HLOS winds should be achievable. When the radar gate straddles
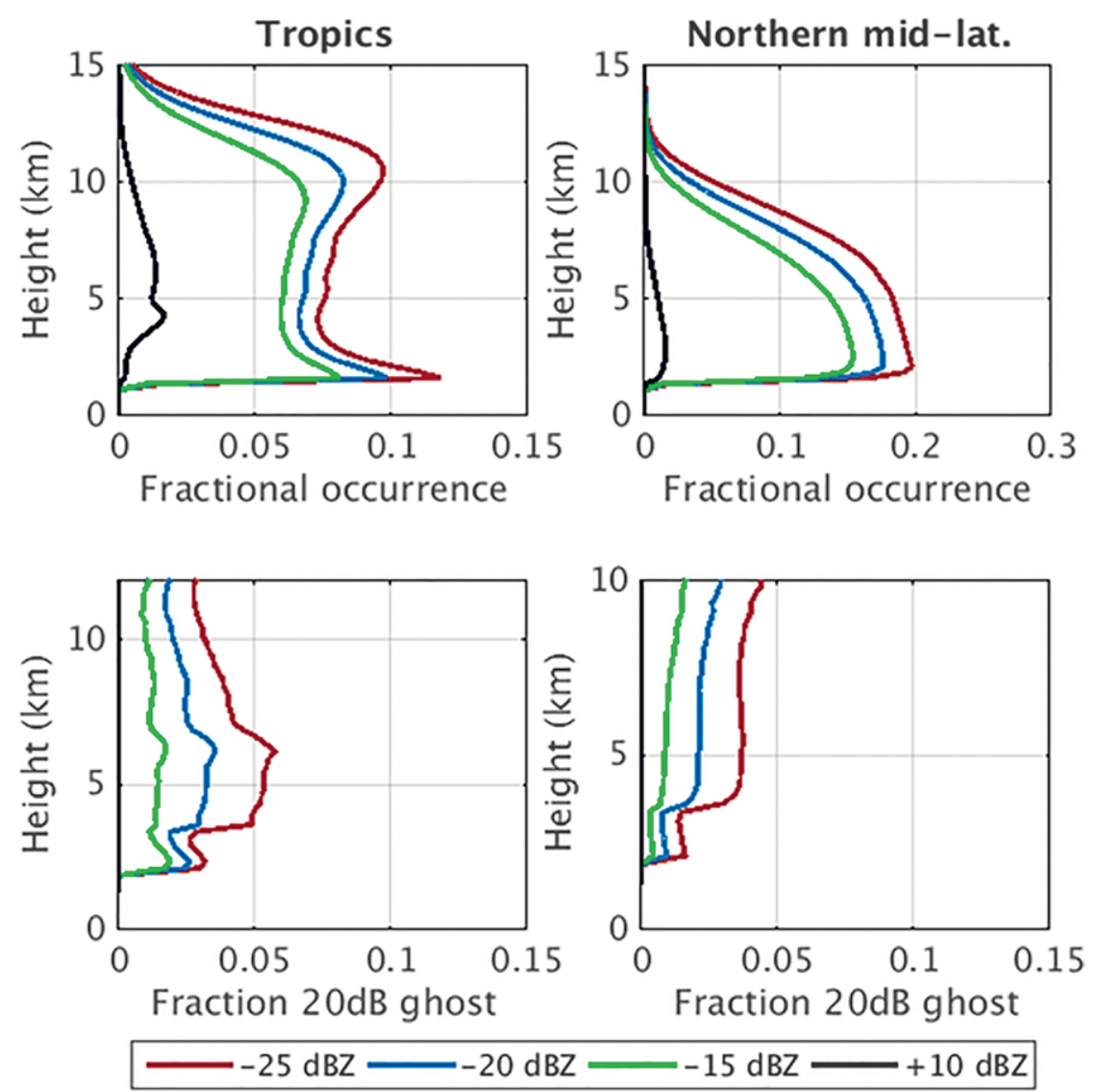

Fig. 4. (top) CloudSat observations of the fraction of the time a cloud is present with a reflectivity exceeding a given threshold as a function of height for an along-ground-track integration length of $20 \mathrm{~km}$. (left) Tropical clouds. (right) Midlatitude clouds between $30^{\circ}$ and $60^{\circ} \mathrm{N}$. (bottom) The fraction of echoes in the top row at each height that have an echo with reflectivity $20 \mathrm{~dB}$ stronger either $2 \mathrm{~km}$ above or below that height (see text for details of how this leads to ghosts). 
the melting layer, the terminal velocity changes rapidly, but such occasions can be flagged by the high values of the depolarization ratio, $\mathrm{LDR}$, resulting from the irregular rocking motion of the wet oblate melting snowflakes.
POTENTIAL SPURIOUS SIGNALS FROM THE DOPPLER RADAR. Ground clutter. Surface clutter contamination can affect the hydrometeor Doppler signal; if the signal-to-clutter ratio (SCR) is $15 \mathrm{~dB}$, it will lead to a $3 \%$ bias of the hydrometeor velocity toward the surface zero velocity. The shape of the clutter signal is determined by the combined effect of the WIVERN antenna pattern, its pulse shape, and the illumination geometry while its intensity is driven by the surface backscattering properties (Meneghini and Kozu 1990). A recent aircraft campaign funded by the European Space Agency (ESA) and conducted in Canada using the National Research Council (NRC) airborne W-band radar has characterized the surface return at WIVERN incidence angles $\left(41^{\circ}\right)$ both for ocean and flat-land surfaces [full details in Battaglia et al. (2017)]. Over ocean the normalized backscattering cross sections $\left(\sigma_{0}\right)$ are over $30 \mathrm{~dB}$ smaller than at nadir with typical values of $-25 \mathrm{~dB}$ but roughly ranging between -35 and $-15 \mathrm{~dB}$ with larger (smaller) values in the presence of strong (weak) wind and when looking upwind (crosswind). Sea surfaces are moderately depolarizing at such angles with an LDR of about $-15 \mathrm{~dB}$. Ocean backscattering properties are characterized by a strong angular dependence but land surfaces are more constant with $\sigma_{0}$ of the order of $-10 \mathrm{~dB}$. Forest-covered and rural surfaces present very similar results, while urban surfaces generate slightly higher values of $\sigma_{0}$.

The clutter expected for a WIVERN configuration when observing a flat surface 
with $\sigma_{0}=0 \mathrm{~dB}$ is illustrated in Fig. $5 \mathrm{a}$ for the WIVERN antenna pattern, which was derived in the ESA-Dora Invitations to Tender (ITT) study (inset of Fig. 5b). The first antenna sidelobe at $0.15^{\circ}$ is $20 \mathrm{~dB}$ below the maximum and is clearly affecting the surface clutter above $1 \mathrm{~km}$ altitude. Clutter signals scale with $\sigma_{0}$ and are therefore expected to be about $10 \mathrm{~dB}(25 \mathrm{~dB})$ lower than those depicted in Fig. $5 \mathrm{a}$ over flat land (the ocean). If snow-covered surfaces have $\sigma_{0}$ lower than $0 \mathrm{~dB}$ (still to be determined by observations), the plot in Fig. 5a suggests that it will be possible to produce snow retrievals similar to those of CloudSat, with clutter contamination only in the last kilometer close to the surface for $Z_{\text {snow }}>-10 \mathrm{~dB} Z$, and at lower altitudes for higher reflectivities. LOS winds must be derived only in regions with large signal-to-clutter ratios $(15 \mathrm{~dB}$ or above). For reflectivities $3 \mathrm{~dB}$ above the minimum detection threshold this means that the surface signal must be lower than $-30 \mathrm{dBZ}$. For characteristic values of sea and land $\sigma_{0}$, this seems to be achievable at heights above 1 and $2 \mathrm{~km}$, respectively.

Cross-polarization interference and the effect of "ghost" echoes. The ability of the polarization diversity scheme to derive wind velocities relies on limiting the coupling between the polarizations both at the hardware level, typically reducing values to $<-25 \mathrm{~dB}$, and while the wave propagates and scatters in the atmosphere. At the WIVERN incidence angles, atmospheric targets like melting hydrometeors and columnar crystals can produce LDRs up to $-12 \mathrm{~dB}$
(Wolde and Vali 2001) while surface clutter tends to depolarize more over land (LDR values of $-9 \pm 3 \mathrm{~dB}$ ) than over sea (characteristic value of $-15 \mathrm{~dB}$; Battaglia et al. 2017). The effect of cross polarization is to produce an interference signal in each copolar channel depending on the temporal shift between the $\mathrm{H}$ and $\mathrm{V}$ pair and the strength of the cross-polar power (which is given by the product of the LDR and the copolar power) and appear as ghost echoes (Battaglia et al. 2013). The phases of ghost echoes are incoherent with respect to the echoes of interest and so do not bias the velocity estimates, but they increase their random error as a function of SGR (Pazmany et al. 1999); as illustrated by the dashed lines in Fig. 3, when the SGR falls to 0 and $-5 \mathrm{~dB}$, this random error increases rapidly for shorter integration lengths. By replacing 2 in 10 of the pulse pairs by a single $\mathrm{H}$ or $\mathrm{V}$ pulse, the LDR of the targets can be monitored and used to flag occasions when there may be cross talk between the $\mathrm{H}$ and $\mathrm{V}$ echoes.

Figure 6 shows simulated WIVERN observations of reflectivity and LDR of a stratiform precipitating system over the Pacific observed on 10 January 2008 and reconstructed by tilting and wrapping the vertical CloudSat curtain so as to be along the WIVERN scanning direction. CloudSat effective reflectivity and attenuation are derived from the $2 \mathrm{C}$-RAIN product. The reconstruction accounts for the WIVERN observation geometry and its antenna pattern, and assumes a $5-\mathrm{km}$ integration length. LDR values sampled from normal distributions are used for rain, ice crystals,
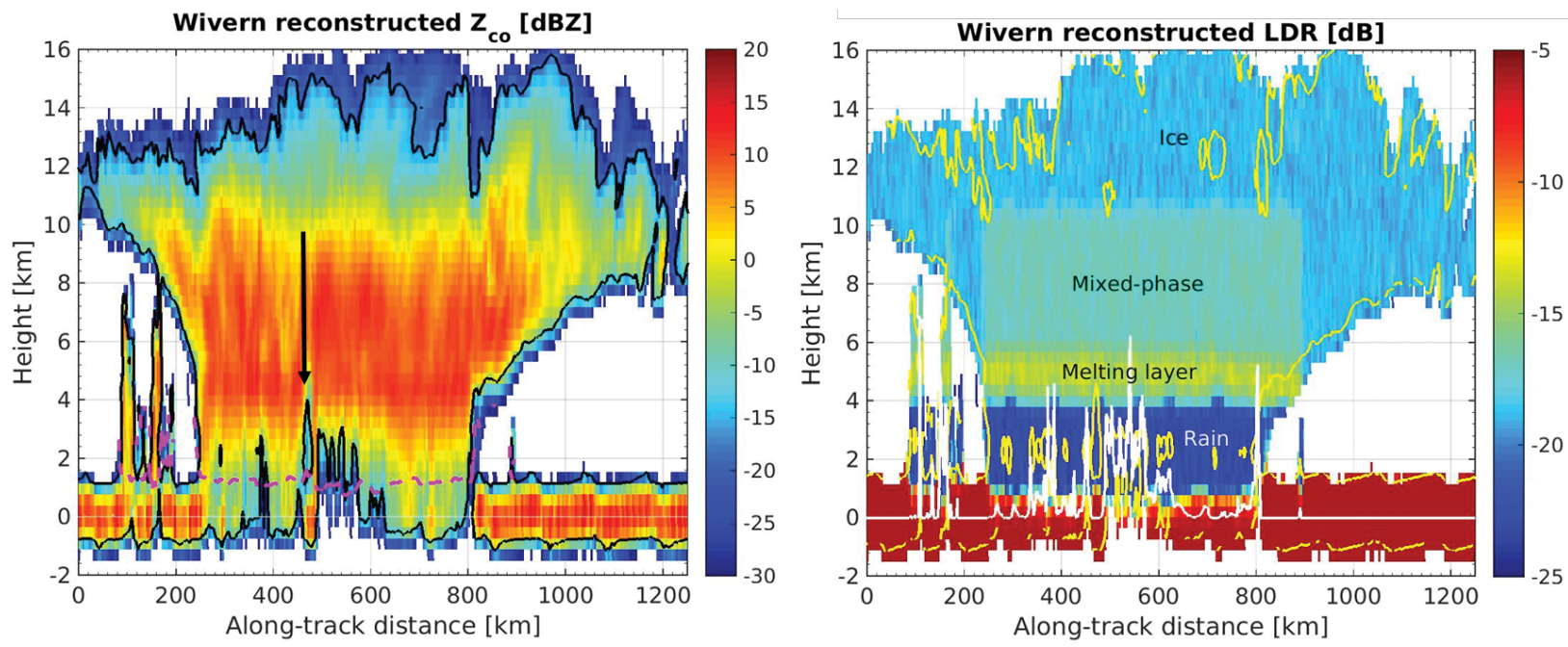

FIG. 6. Reconstructed WIVERN reflectivity from a stratiform precipitation event observed by CloudSat over the western Pacific between $19^{\circ}$ and $7^{\circ} \mathrm{S}$ using a $5-\mathrm{km}$ integration length. (left) The black dashed line corresponds to the contour where the standard deviation of the Doppler velocity is $\mathbf{2} \mathbf{m ~ s}^{-1}$ while the magenta line corresponds to the region where the $S C R=20 \mathrm{~dB}$. A value of $T_{\mathrm{hv}}=20 \mu \mathrm{s}$ has been assumed. (right) As in the left panel, but for the WIVERN LDR reconstructed from climatological a priori LDR. The gray lines here correspond to $S G R=3 \mathrm{~dB}$ while the white line is the rain rate (in $\mathrm{mm} \mathrm{h}^{-1}$ ) from the CloudSat 2B-RAIN product. 


\section{GHOST ECHOES}

The formation of ghosts is illustrated in a bounce diagram (Fig. SB2) for the profile indicated by the black arrow in Fig. 6. The cross-polar (V) component of the transmitted $\mathrm{H}$ pulse reflected at the point $S_{\text {, }}$ on the surface interferes with the rain copolar signal of the second $(\mathrm{V})$ pulse transmitted after $T_{h v}=20 \mu$ s and scattered along the line $A_{1} B_{1}$ in timedistance space. In the same manner, the trailing edge of the pulse reflected in the cross channel at the point $S_{2}$ adds up to the rain signal along the line $A_{2} B_{2}$. At the $V$ receiver the copolar $V$ signals backscattered by rain in the gray-shaded rhombus $A_{1} A_{2} B_{2} B_{1}$ region are overcome by the ground clutter cross-polar return of the first pulse (blue-shaded regions). These ghost signals appear in the second pulse, centered around an altitude of $c T_{\text {hv }} \cos \left(\theta_{\text {inc }}\right) / 2\left(2.25 \mathrm{~km}\right.$ for this $\left.T_{\text {hv }}\right)$. Because the ground clutter is uncorrelated with the rain signals, this only worsens the Doppler velocity estimates according to the SGR (Fig. 3). The same phenomenon can occur when strong vertical reflectivity gradients are present concurrently with strongly depolarizing targets (e.g., red-shaded region).

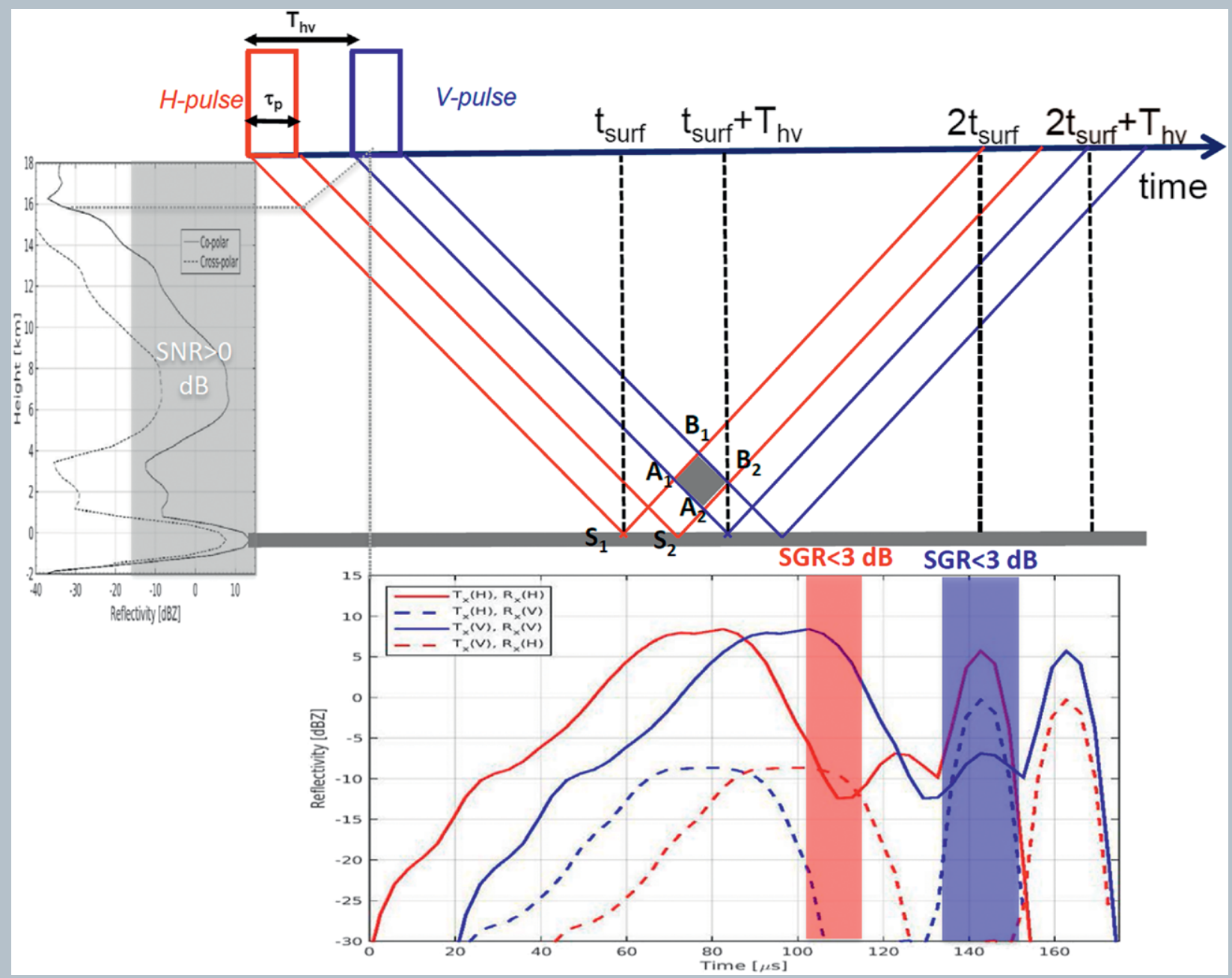

FIG. SB2. A bounce diagram showing how depolarizing returns from the surface can cause cross talk between the $\mathbf{H}$ and $\mathbf{V}$ channels giving ghost echoes. Such echoes do not bias the estimated velocity but only lead to an increase in the random error.

melting-layer particles, and mixed-phase clouds, with means of $-23,-19,-14$, and $-17 \mathrm{~dB}$ and standard deviations of $2,1.5,1.5$, and $1.5 \mathrm{~dB}$, respectively. These values have been selected based on a climatology collected at the Chilbolton Observatory, Chilbolton, United Kingdom. Clutter with the shape shown in Fig. 5a and representative of flat-land surfaces, having $\sigma_{0}$ normally distributed with a mean value of $-8 \mathrm{~dB}$ and a standard deviation $4 \mathrm{~dB}$, has been included. The reflectivity (Fig. 6a) clearly shows a region of strong attenuation in correspondence to the precipitation core $\left(\sim 2-6 \mathrm{~mm} \mathrm{~h}^{-1}\right)$ located around $600 \mathrm{~km}$. The black line contours the 
region where Doppler velocity estimates are expected to have accuracies better than $2 \mathrm{~m} \mathrm{~s}^{-1}$ when adopting a $T_{\text {hv }}$ equal to $20 \mu \mathrm{s}$. The SCR is typically $>20 \mathrm{~dB}$ (magenta line) for heights above $2 \mathrm{~km}$ where the bias in velocities will be negligible. Ghost echoes (see the "Ghost echoes" sidebar) are expected when the SGR is $<3 \mathrm{~dB}$ (yellow line in right panel) and are confined to the high-reflectivity gradients at the cloud boundaries (where Doppler will be too noisy anyway) and close to the surface (that would be much reduced over the sea).

A month of CloudSat data (January 2008) have been used to simulate WIVERN profiles and the ghosts generated by $T_{\mathrm{hv}}$ values of 5,20 , and $40 \mu \mathrm{s}$, taking into account the SNR, the SGR, and the SCR for each $5-\mathrm{km}$ along-track integration length in order to assess the fraction of profiles for which WIVERN is expected to produce winds with accuracy better than $2 \mathrm{~m} \mathrm{~s}^{-1}$ (Fig. 7). The fraction is much lower for the $5-\mu \mathrm{s} T_{\mathrm{hv}}$ values because the increased noise error maps into a large velocity error. Overall, Fig. 7 shows that in the midtroposphere $(3-8 \mathrm{~km}$ ) WIVERN would provide a useful measurement $10 \%$ of the observation time, but this amount is reduced to $5 \%$ over land at heights near 2 and $4 \mathrm{~km}$ where the bright land surfaces produce ghost echoes for $T_{\text {hv }}$ of 20 and $40 \mu \mathrm{s}$, respectively, indicating that $20 \mu$ s may be optimal.

Ground-based validation of theoretically predicted wind errors and biases. The degree to which ghost echoes and/or vertical gradients in reflectivity combined with vertical wind shear can lead to increased random errors or biases in the wind estimates made from space by WIVERN can be assessed using recent observations made with the $94-\mathrm{GHz}$ radar at Chilbolton in southern England pointing $45^{\circ}$ off zenith with a time resolution of $6 \mathrm{~s}$ and gate length of $60 \mathrm{~m}$. The case of 27 June 2017 (Figs. 8a-d) is chosen because of the large gradient in received power exceeding $20 \mathrm{~dB}$ for the $3-\mathrm{km} / 20-\mu \mathrm{s}$ separation of the $\mathrm{H}-\mathrm{V}$ pulse pair (Fig. 8a); this will lead to $S G R$ ratios of 0 and $-5 \mathrm{~dB}$ for LDR values of -20 and
$-15 \mathrm{~dB}$ (not shown; but in the melting layer at $4-\mathrm{km}$ range, they reached $-15 \mathrm{~dB}$, resulting in an SGR of $-5 \mathrm{~dB}$ at $7.5-\mathrm{km}$ range). The velocity estimated with $T_{\text {hv }}=20 \mu \mathrm{s}$ (Fig. 8c) at a height of $4.54 \mathrm{~km}$ where SGR is at its lowest is plotted in black in Fig. 8d (upper trace), whereas the "true" velocity from the $\mathrm{H}-\mathrm{H}$ pulse pairs separated by $160 \mu$ s (when there will be no ghost echoes) is in red; the increased gate-to-gate random noise introduced by the ghosts in the black trace when SGR is low is very clear when compared to the smooth red trace. The lower trace in Fig. 8d shows that the observed increases in the rms error for $T_{\text {hv }}=20 \mu$ s agree very well with two independent theoretical predictions of the error (see Fig. 3); one is based on the SNR and SGR computed via the LDR estimate, and a second is based on the drop in the observed correlation between the $\mathrm{H}-\mathrm{V}$ returns because of the increase in the noise. This plot confirms that ghosts increase the random error of the wind estimate but do not introduce any bias. Ghosts are observed relatively frequently from the ground, because of the $\sim 10$ - $\mathrm{dB}$ change in received power from the same target at a range of 1 and $3 \mathrm{~km}$. So they are useful for validating the theory, but ghosts should be much less frequent from space, because of the negligible fractional change in the range of the targets (see top-right

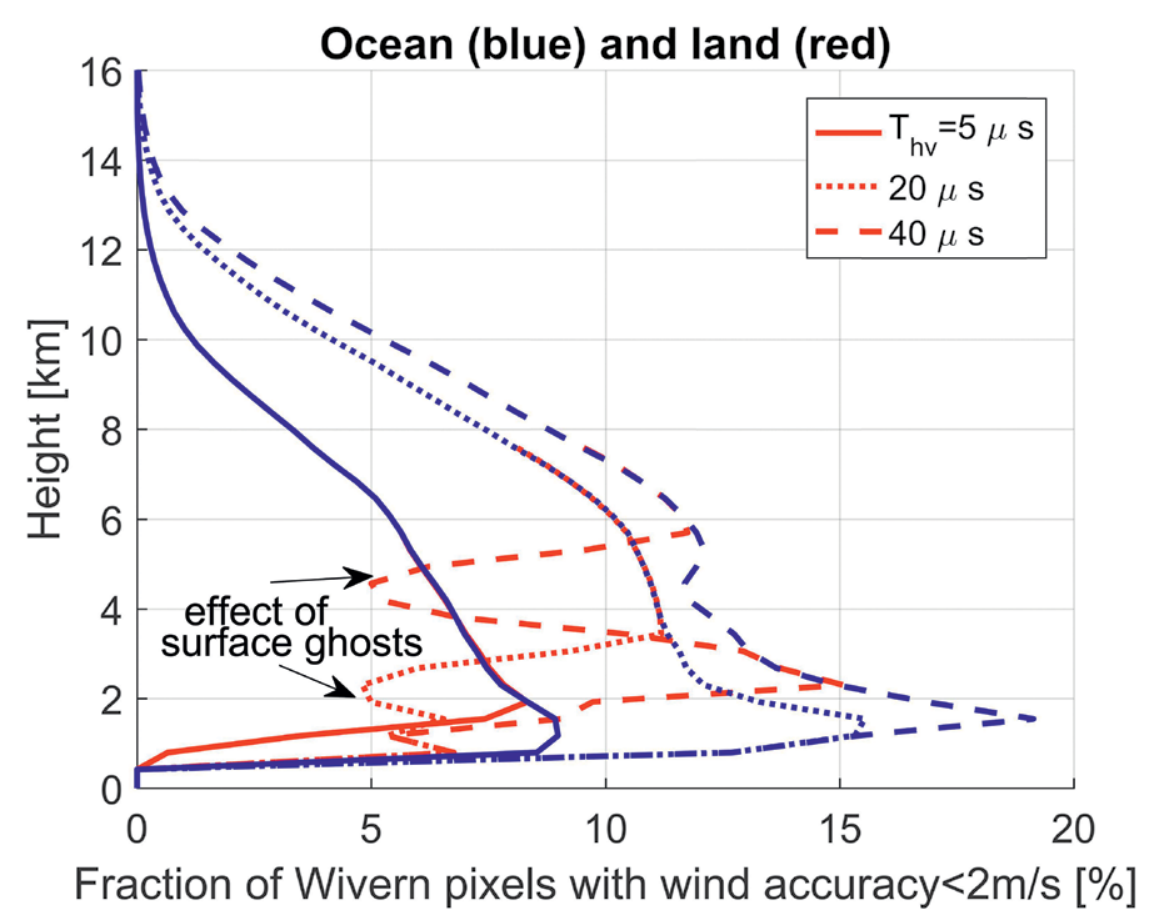

FIG. 7. The fraction of WIVERN profiles, integrated along track for $5 \mathbf{~ k m}$, where winds at a given height can be derived with an accuracy of $2 \mathbf{~ m ~ s}^{-1}$ for various $T_{\text {hv }}$ values, derived from CloudSat profiles with an assumed LDR value and recent observations of surface clutter returns over the ocean (blue) and over land (red), excluding mountains and cities. Note the effect of ghost returns from the surface affecting the retrieval at heights dependent upon $T_{\text {hv }}$. 

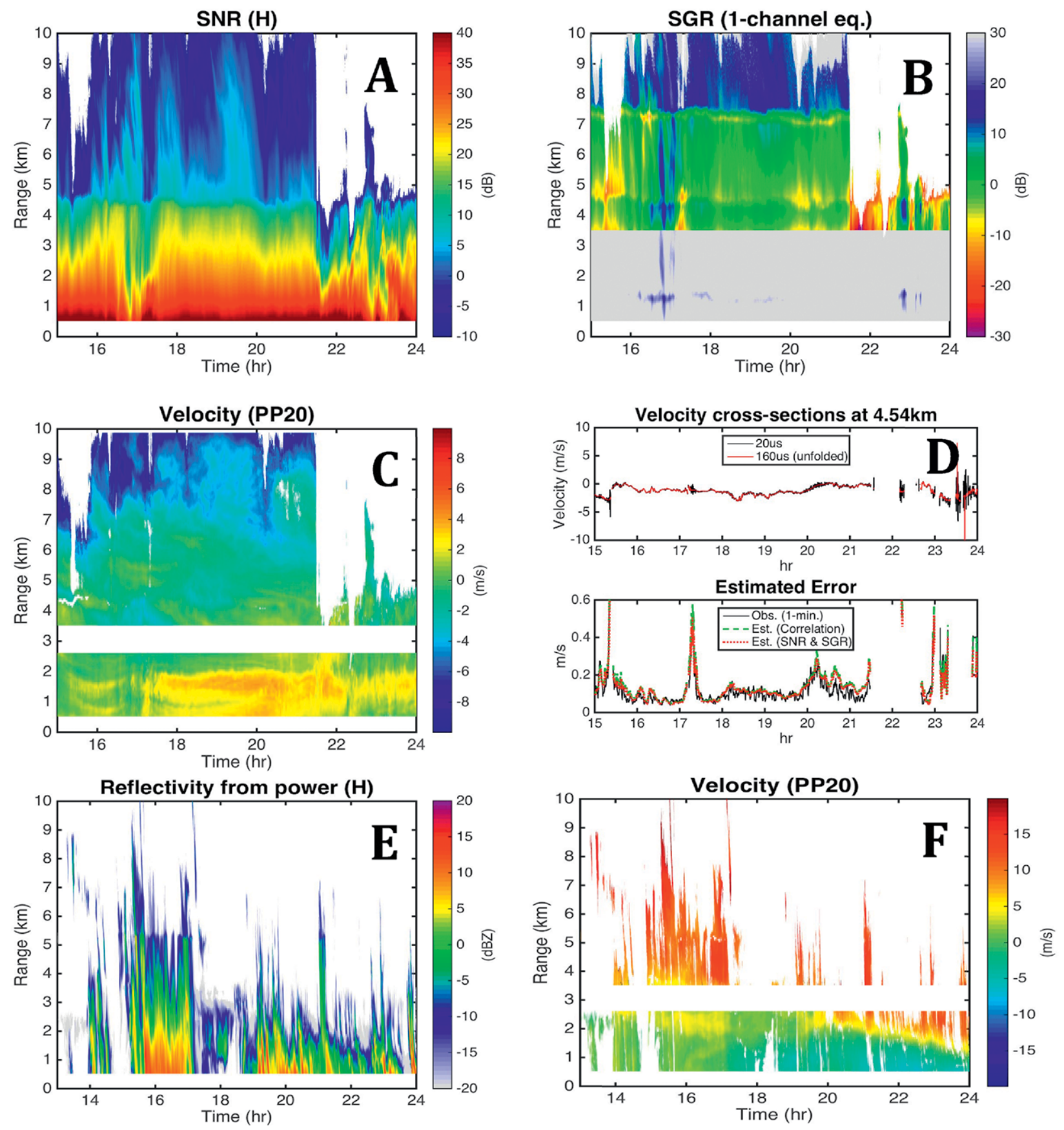

FIG. 8. Observations at Chilbolton at $45^{\circ}$ elevation showing the increased random error in the velocity estimates due to ghosts on 27 Jun 2017: (a) the SNR in the H channel; (b) the SGR in the H channel due to the depolarization of the V channel shifted by $3 \mathrm{~km}$ in range; (c) PP20, which is the velocity derived from the $\mathrm{H}-\mathrm{V}$ [20 $\mu \mathrm{s}(3 \mathrm{~km})^{-1}$ ] pulse pairs with a folding velocity of $40 \mathrm{~m} \mathrm{~s}^{-1}$; and (d) top trace showing the "true" velocity (red line) derived from a pulse separation of $160 \mu \mathrm{s}$ at a height of $4.54 \mathrm{~km}$ and the PP20 velocity from the H-V pulses (black). Note the increased noise in the black trace when SGR and SNR are low. The bottom trace in (d) shows the observed rms error obtained by comparing the true PPI60 velocity with the PP20 H-V velocity (black), and the close agreement with the theoretical errors from the SNR and SGR (red), and from the H-V correlation (green). (e),(f) The high wind shear case accompanied by large vertical reflectivity gradients observed on 28 Aug 2017 . For details see the text.

panel in Fig. 4). Biases in the radar-derived winds may arise when there is a vertical wind shear that coincides with a large vertical gradient of radar reflectivity; this is the case in Figs. $8 \mathrm{a}$ and 8c, where at a slant range of $4.5 \mathrm{~km}$ the reflectivity across the bright band changes by $10 \mathrm{~dB}$ in $1 \mathrm{~km}$ and the vertical wind shear is about 
$5 \mathrm{~m} \mathrm{~s}^{-1} \mathrm{~km}^{-1}$. These radar observations are taken every $6 \mathrm{~s}$ with a gate length of $60 \mathrm{~m}$. From the average winds at this resolution, the true velocity for a WIVERN sample volume of 800 -m length by $10 \mathrm{~min}$ (equivalent to a horizontal distance of $10 \mathrm{~km}$ from the satellite if the horizontal advection velocity is $1 \mathrm{~km} \mathrm{~min}^{-1}$ ) can be computed and the bias derived by comparing this true velocity with the reflectivity-weighted mean velocity that would be detected by WIVERN. From this image WIVERN would obtain 550 wind samples with an rms LOS wind error of $0.16 \mathrm{~m} \mathrm{~s}^{-1}$ and an average bias of $0.07 \mathrm{~m} \mathrm{~s}^{-1}$, but for data assimilation purposes the data would be thinned. The case above was chosen because of the marked bright band, but Figs. $8 \mathrm{e}$ and $8 \mathrm{f}$ illustrate the case of 28 August 2017, when a region of wind shear of $20 \mathrm{~m} \mathrm{~s}^{-1} \mathrm{~km}^{-1}$ and reflectivity gradients of up to $20 \mathrm{~dB} \mathrm{~km}^{-1}$ descended by $2-3 \mathrm{~km}$ in $10 \mathrm{~h}$. The biases can also be predicted from changes in velocity from neighboring samples at the WIVERN resolution and the observations are rejected when this exceeds $0.3 \mathrm{~m} \mathrm{~s}^{-1}$. The result is that $20 \%$ of the WIVERN samples are rejected, and the remaining WIVERN observations have a bias of $0.05 \mathrm{~m} \mathrm{~s}^{-1}$ and an rms error of $0.34 \mathrm{~m} \mathrm{~s}^{-1}$.

Nonuniform beam filling (NUBF). For fast-moving spaceborne Doppler radar, reflectivity gradients within the radar sampling volume can introduce a significant source of error in Doppler velocity estimates (Tanelli et al. 2002). When adopting slant-viewing geometry, the situation is illustrated in Fig. 5b, with the shading of the WIVERN sampling volume indicating the strength of the backscattered signal. The red and green arrows indicate the apparent velocity introduced to the WIVERN volume as a result of the motion of the satellite (green toward and red away from the satellite); as a result, for the case illustrated, a downward bias will be produced. Notional studies have demonstrated that such biases can be mitigated by estimating the alongtrack reflectivity gradient (Schutgens 2008; Kollias et al. 2014; Sy et al. 2014). For WIVERN the relevant gradients are those along the direction in the plane generated by the satellite velocity and by the antenna boresight and are orthogonal to the latter (identified by $\eta$ in Fig. 5b). As a consequence, NUBF effects are linked to reflectivity gradients along different directions depending on the scanning position of the rotating antenna, with NUBF velocity biases expected to be linearly proportional to such reflectivity gradients with a coefficient of the order of $0.1-0.15 \mathrm{~m} \mathrm{~s}^{-1} \mathrm{~dB}^{-1} \mathrm{~km}$ (Battaglia and Kollias 2015a). When side looking, the relevant reflectivity gradients are those along track, which can be estimated from the reflectivities measured along the scanning track and which are used to mitigate the NUBF effect. However, such mitigation is increasingly less feasible when moving from side to forward-backward-looking angles where the relevant reflectivity gradients correspond to a direction that is orthogonal to the scanning track. But, thanks to the WIVERN conical scanning geometry, on average, the biases looking in opposite directions with respect to the satellite motion are separated by $\sim 2 \mathrm{~min}$ and cancel out so NUBF leads only to an increase in the random error of the wind. A high-resolution $(0.5 \mathrm{~km}$ horizontally and $0.3 \mathrm{~km}$ vertically) synthetic reflectivity field obtained from a Weather Research and Forecasting (WRF) Model simulation of Hurricane Isabel has been used to estimate the NUBF-induced errors of WIVERN measurements. Preliminary results show that errors should be less than $0.5 \mathrm{~m} \mathrm{~s}^{-1}$ for sidelooking and $2 \mathrm{~m} \mathrm{~s}^{-1}$ for forward-backward-looking angles. More work is needed in order to properly characterize the variability of the wind and of the $94-\mathrm{GHz}$ reflectivity field at the WIVERN subpixel scale. Datasets obtained via airborne or ground-based $94-\mathrm{GHz}$ Doppler radars could be used to test the detrimental NUBF effect on Doppler measurements.

Pointing accuracy. The rotating antenna will introduce a sinusoidal component of the satellite velocity with an amplitude of about $5,000 \mathrm{~m} \mathrm{~s}^{-1}$. If the bias is to be less than $0.5 \mathrm{~m} \mathrm{~s}^{-1}$, then the radar electrical boresight elevation and azimuthal angles should be known to $<100 \mu \mathrm{rad}$. If the radar is used as an altimeter, the elevation angle can be continually monitored by measuring the range as the antenna scans over the sea; for a slant range of $651 \mathrm{~km}$, an error of $100 \mu \mathrm{rad}$ would manifest itself as an apparent change in range of the sea surface of $42 \mathrm{~m}$. For a point target with an SNR $>20 \mathrm{~dB}$, Skolnik (1981, p. 402) shows that changes in the time of the leading edge of the return echo can be estimated to within $5 \%$ of the echo rise time; simulations using distributed scatterers on the sea surface confirm that this accuracy can be maintained by averaging 100 pulses (10 km along the ground track). Turning to the requirement to know the azimuthal angle to $100 \mu \mathrm{rad}$, equivalent to a distance along the scanning ground track of just $65 \mathrm{~m}$, or about one-tenth of the beamwidth, an error of $100 \mu \mathrm{rad}$ in pointing knowledge will result in a sinusoidal velocity error with maxima of $\pm 0.5 \mathrm{~m} \mathrm{~s}^{-1}$ when pointing across track. More studies are needed on this topic, but we propose two approaches. First, when pointing precisely across track, ground clutter will appear to be stationary and averaging over many scans should 
identify the precise angle at which this happens, and, second, we will use regions of light winds where the European Centre for Medium-Range Weather Forecasts (ECMWF) analysis provides winds accurate to better than $1 \mathrm{~m} \mathrm{~s}^{-1}$ to make small adjustments to the azimuthal-pointing knowledge to remove the systematic biases when pointing across track.

Multiple scattering. When dealing with spaceborne millimetric radars, in the presence of highly attenuating media, the multiple-scattering signal can overwhelm the single-scattering contribution (Battaglia et al. 2010) with very detrimental effects both on retrieval and Doppler products (Battaglia and Kollias 2014). Studies based on CloudSat have demonstrated that multiple scattering is not negligible in the presence of high-density ice (hail and graupel) or moderate/ intense rain (Battaglia et al. 2011). With an LDR mode, segments of the profiles affected by multiple scattering can be easily flagged (e.g., by the condition LDR > $-10 \mathrm{~dB}$; see Battaglia et al. 2007) and excluded from further wind analysis. Indeed, air motions in these conditions would not be assimilated into the model even if they had been properly retrieved, as they are not representative of the large-scale flow and are transient features compared to the revisit time of the satellite.

\section{THE IMPACT OF WIND OBSERVATIONS ON GLOBAL NWP MODELS. The main im-} pact of the WIVERN wind observations should be realized through their assimilation into global NWP models. The forecasting sensitivity to observations (FSOI) technique (Langland and Baker 2004), implemented in the ECMWF model by Cardinali (2009), is a very powerful tool that enables, for the first time, quantification of the impact of individual observations that are assimilated into the NWP forecast model in reducing the "forecast error" obtained by comparing the $T+24$ forecasts of temperature, wind, humidity, and surface pressure with their corresponding analyses. The contributions of the top-five observation types in reducing this forecast error for the Met Office, ECMWF, and Météo-France global models are displayed in Table 3 . The results show that both the in situ aircraft observations and the atmospheric motion vectors (AMVs, the winds derived from the movement of cloud or water vapor features in successive satellite images) make an important contribution to reducing forecast errors, second only to the humidity and temperature structure provided by the IR and microwave sounders.

The initial high-resolution AMV wind observations are thinned in the ECMWF global model to provide, at most, a single wind estimate for each $200 \mathrm{~km} \times 200 \mathrm{~km}$ horizontal "box," a vertical thinning of 50-175 hPa that varies with height, and a 30 -min temporal thinning. This thinning is used to account for the spatial and temporal correlation of AMV winds errors over large distances due to errors in the height assignment. The figures for the Met Office are similar: $200 \mathrm{~km} \times 200 \mathrm{~km}, 100 \mathrm{hPa}$, and $2 \mathrm{~h}$. ECMWF blacklists AMV winds over land below $500 \mathrm{hPa}$, while the Met Office is not quite so strict with a height limit over land usually closer to $600 \mathrm{hPa}$ north of $20^{\circ} \mathrm{N}$. If observations are assimilated at too high a horizontal density, the fact of not accounting for spatial correlations of observation errors in the analysis can also degrade the resulting forecasts (Liu and Rabier 2002). Aircraft winds do not suffer from problems associated with strong spatial correlations and screening over land, and in the ECMWF model are used for a height range that extends down to within $1 \mathrm{~km}$ of the surface and are currently thinned to $70 \mathrm{~km}$ in the horizontal and $15 \mathrm{hPa}$; this will be reduced to $35 \mathrm{~km}$ and $7.5 \mathrm{hPa}$ in 2018 . Currently, about half of all aircraft winds are below $500 \mathrm{hPa}$. The case studies discussed in Fig. 8 suggest that the radar-derived winds should have similar error characteristics to aircraft winds but may be rather larger because of their 800-m vertical resolution.

Table 4 compares the contributions of the AMV winds and the in situ aircraft measurements 
to the ECMWF global model and shows that when AMV winds are assimilated they are, on average, assigned a random error of $4.6 \mathrm{~m} \mathrm{~s}^{-1}$ for the zonal component of the wind, but for the in situ aircraft winds the error is only $2.3 \mathrm{~m} \mathrm{~s}^{-1}$. Combined with the larger thinning of the AMV winds, the net result is that only $4 \%$ of the AMV observations are assimilated as opposed to $36 \%$ of the aircraft observations. The CloudSat analysis summarized in Figs. 4 and 7 indicates that about 1.3 million winds with a resolution of $20 \mathrm{~km}$ along track would be obtained each day for WIVERN. If these were thinned to $50 \mathrm{~km}$, similar to the ECMWF value planned for aircraft winds in 2018, then the number assimilated could be about 500,000 per day. By comparison with the figures in Table 4, this suggests that their impact on the forecast should be significant.

The winds from WIVERN are only line of sight but Horányi et al. (2015a) have demonstrated that, with a state-of-the-art data assimilation system and real observations, HLOS winds such as would be obtained from an aircraft provide about $70 \%$ of the impact of a vector wind, and that in the tropics the impacts of wind data are much greater than the mass information. McNally (2002) provides further evidence for the potential impact of in-cloud winds. He investigated the sensitivity of the weather forecasts to errors in the analysis of the current atmospheric state that subsequently develop into significant medium-range forecast errors. The main obstacle was the presence of cloud in these "sensitive" areas; depending on the
TABLE 4. The numbers of raw and assimilated wind observations for ECMWF for $u$-wind data and their mean assigned error for an arbitrary 12-h-long window data assimilation cycle starting at 0000 UTC I Oct 2016.

\begin{tabular}{|lrrr|} 
& Total & AMV & \multicolumn{1}{c|}{ A/C } \\
\hline Raw (pre-QC) & $6,527,000$ & $3,573,381 ;$ & 495,$000 ;$ \\
& & $54.7 \%$ & $7.6 \%$ \\
\hline Assimilated & 424,000 & 144,$099 ;$ & 179,$550 ;$ \\
& & $34.0 \%$ & $42.3 \%$ \\
\hline Fraction assimilated & & $4.0 \%$ & $36.3 \%$ \\
\hline Assigned error $\left(\mathbf{m ~ s}^{-1}\right)$ & & 4.61 & 2.27 \\
\hline
\end{tabular}

amount and altitude of cloud cover, the information from infrared (IR) sounders (advanced or otherwise) could be severely limited.

If winds are to be assimilated, it is extremely important that the systematic errors of the observations are not too large relative to the random errors. Simulations carried out to predict the potential impact of the winds from the Aeolus satellite by Horányi et al. (2015b) have shown that assimilating winds that are biased by $1-2 \mathrm{~m} \mathrm{~s}^{-1}$ when the random error standard deviation is around $2 \mathrm{~m} \mathrm{~s}^{-1}$ will actually degrade the forecast unless the bias can be estimated and removed prior to assimilation. Our analysis suggests that winds from WIVERN should only be biased when they are affected by ground clutter and that such regions should be easy to identify.

The mean observation error and the number of AMV winds from Meteosat-10 that were assimilated into the Met Office model for the month of December
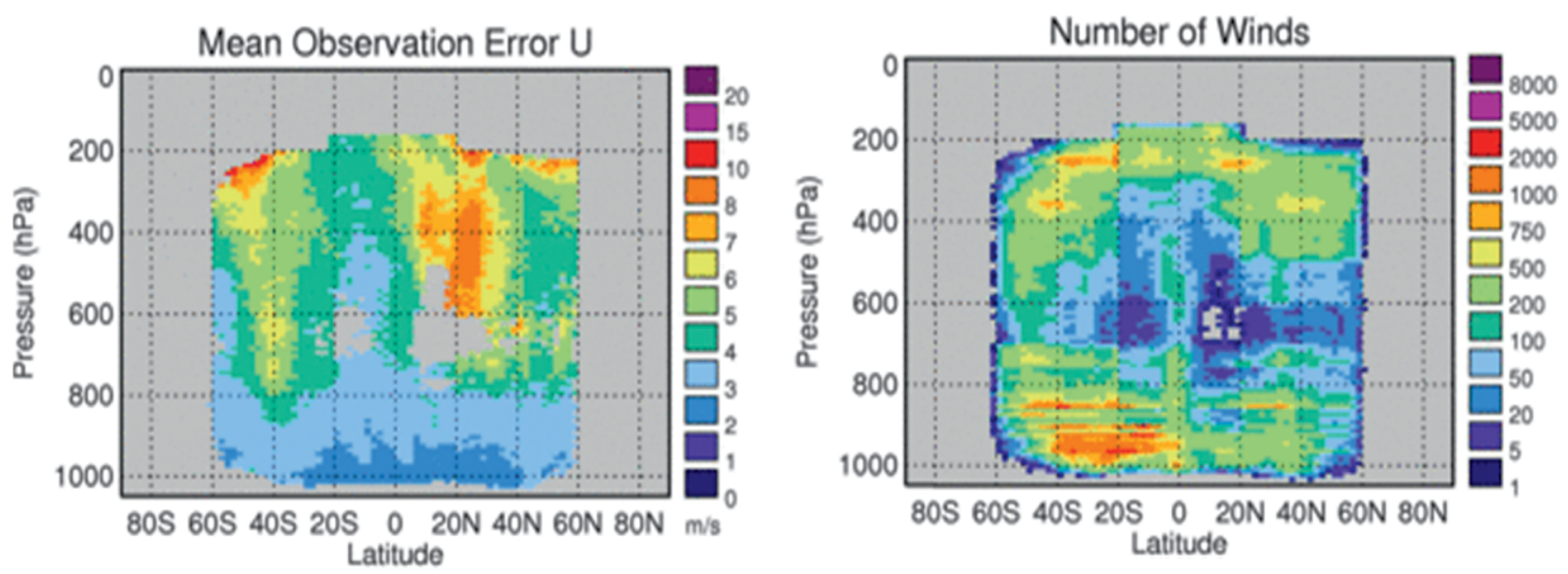

Fig. 9. Statistics of the AMV winds assimilated into the Met Office global model from Meteosat- 10 for the month of Dec 2016. (left) The mean assigned observation error of $U\left(\mathrm{~m} \mathrm{~s}^{-1}\right)$ as a function of pressure and latitude. (right) The number of winds assimilated as a function of pressure. The maximum numbers are found at around $900 \mathrm{hPa}$ over the Southern Ocean, followed by heights of 200-400 hPa at all latitudes. Note the relatively low number of winds from the midlevels. 
are plotted in Fig. 9. The AMV error is a combination of error in the tracking step and an error in speed due to an uncertainty in the height assignment as discussed by Salonen et al. (2015); Forsythe and Saunders (2008) describe how the assigned AMV velocity error increases with the vertical wind shear in the model. For heights above $500 \mathrm{hPa}$ and for all latitudes, the mean observation error is mostly in the range $5-9 \mathrm{~m} \mathrm{~s}^{-1}$. The maximum number of assimilated winds is found at around $900 \mathrm{hPa}$ over the Southern Ocean, followed by heights of $200-400 \mathrm{hPa}$ at all latitudes, with a lower number of winds in midlevels. The vertical distribution of ECMWF-assimilated winds is also bimodal with fewer winds between 400 and $700 \mathrm{hPa}$. Analysis of CloudSat data (Figs. 4 and 7) suggests that one advantage of the WIVERN winds should be the absence of the current midlevel gap in coverage.

The actual numbers of AMV $U$-component winds assimilated into the ECMWF model during a 12-h cycle in October 2016 are displayed in Fig. 10 for each $10^{\circ} \times 10^{\circ}$ area over the globe. The numbers are expressed as the number of observations per $10^{6} \mathrm{~km}^{2}$ area with the data having been thinned into $200 \mathrm{~km} \times 200 \mathrm{~km}$ "boxes" in the horizontal, so that along the equator, a value of 100 would be equivalent to four winds per box during the 12 -h period. When predicting the performance of WIVERN, we assume a thinning to $80 \mathrm{~km}$, close to the current ECMWF value for aircraft winds, and use the CloudSat data to calculate for every $80-\mathrm{km}$ along-track segment how often there is a cloud echo of at least $5-\mathrm{km}$ length where the reflectivity exceeds $-18 \mathrm{dBZ}$, for which (from Fig. 3) we expect the velocity error to be less than $2 \mathrm{~m} \mathrm{~s}^{-1}$. CloudSat has only a small footprint at nadir, so to simulate the $800-\mathrm{km}$-wide circular ground path, we multiply these numbers by 11 , and calculate on average the number of winds per $10^{6} \mathrm{~km}^{2}$ area during a $12-\mathrm{h}$ period as displayed in Fig. 10. This figure indicates that the number of WIVERN winds assimilated should be of similar magnitude to the current AMV winds.

Recent experience at Météo-France has shown that increasing the vertical resolution of the observations in the 4D-Var data assimilation system of the global Action de Recherche Petite Echelle Grande Echelle (ARPEGE) NWP model has always had a positive impact in terms of analyses and forecasts, even though vertical correlation errors are neglected. One example is the increase of vertical resolution of Global Navigation Satellite System (GNSS) radio-occultation (RO) bending angle measurements obtained from limb sounding instruments. For each occultation, about 200 measurements are available between $50 \mathrm{~km}$ and the Earth's surface, and when the number assimilated was increased by a factor of 4 , the fit of the model to the observations was improved both in the analyses and in the short-range forecasts of the model. A second study involved the impact of high-resolution radiosondes when the sonde data were sampled to reflect the vertical grid of the ARPEGE model, and again there was a better fit of the model to the observations both for the analysis and the background. These findings indicate the additional benefit to NWP from an active radar providing profiles of winds at each kilometer height level through clouds, rather than a single wind measurement from near cloud top from passive sensors.
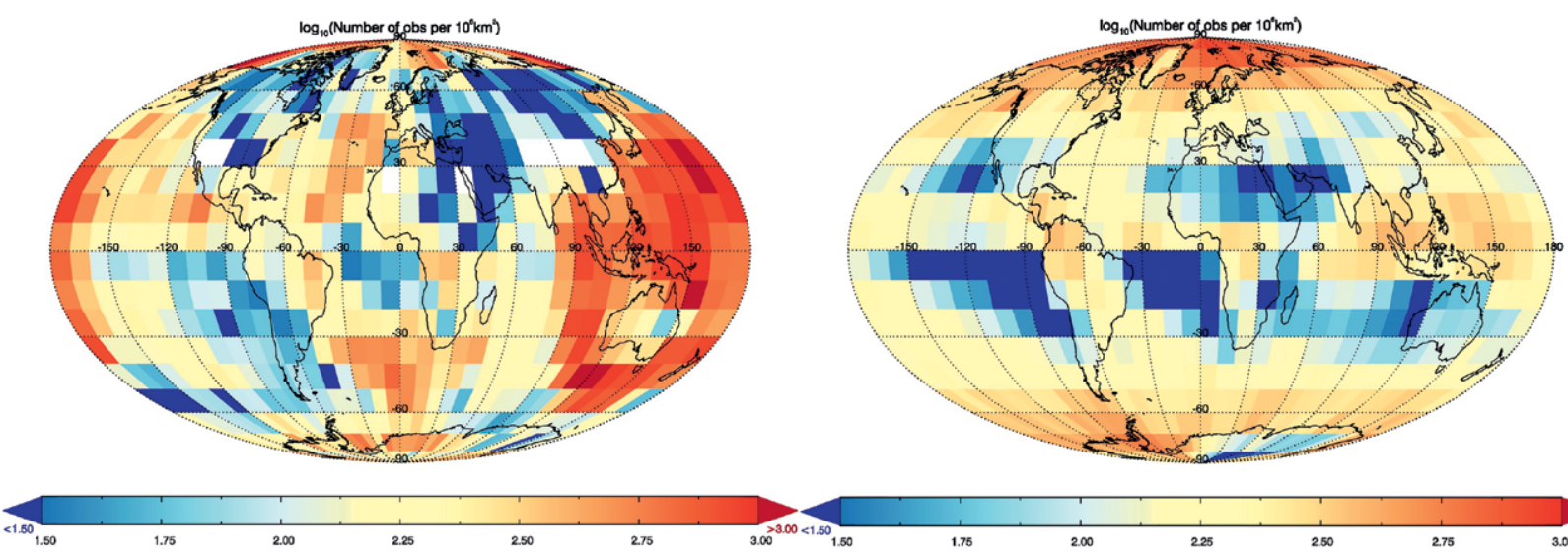

2.00 2.25 2.50 275 $3.00^{>3.00}$

FIG. 10. Comparison of the number of assimilated AMV winds in the ECMWF model and the predicted number of WIVERN winds. (left) The number of assimilated AMV (U wind) observation counts for the I Oct 2016 long window data assimilation (LWDA) cycle (I2-h window) per $10^{6} \mathrm{~km}^{2}(1,000 \mathrm{~km} \times 1,000 \mathrm{~km}$ box). Data are thinned to one observation per $200 \mathrm{~km} \times 200 \mathrm{~km}$ box per height level. (right) As for ECMWF, but the predicted number for WIVERN-simulated winds using CloudSat data with Z > - $17 \mathrm{dBZ}$ for 5-km along-track integration, scaled appropriately for WIVERN sensitivity and increased swath. One observation is counted for each $80 \mathrm{~km} \times 80 \mathrm{~km}$ box. 
ADDITIONAL PRECIPITATIONAND CLOUD PRODUCTS. The main thrust of the WIVERN mission is to provide winds, but the satellite would also measure profiles of reflectivity over the $800-\mathrm{km}$-wide ground track. CloudSat, with its approximately $1-\mathrm{km}$ nadir-only footprint, has provided a unique cloud and IWC climatology that has been invaluable for validating NWP and climate models (e.g., Li et al. 2012) and also the best climatology of light rainfall over the oceans (e.g., Berg et al. 2010; L'Ecuyer and Stephens 2002; Haynes et al. 2009). The rainfall is estimated by measuring the attenuation of the ocean surface return for the nadir-pointing CloudSat, but for WIVERN the ocean surface return at $41^{\circ}$ incidence is much lower, so heavy rain will totally attenuate the surface return, and rainfall estimates will probably be restricted to lighter rainfall. Much of the snowfall over polar regions has values of $Z$ well below $20 \mathrm{dBZ}$ and cannot be detected by the radars on the GPM Core Observatory satellite, but, with its sensitivity limit of $-30 \mathrm{dBZ}$, CloudSat has provided the best global snowfall climatology to date (e.g., Liu 2008; Palerme et al. 2014). The performance of WIVERN for measuring snowfall will depend critically on the level of ground clutter and the radar reflectivity of the snow (see Fig. 5). More work is required to establish the accuracy and errors of rain and snowfall rates from WIVERN. Finally, Janisková et al. (2012) and Janisková (2015) have demonstrated that the assimilation of CloudSat reflectivities into the ECMWF model has a slight positive impact on the subsequent forecast; we can expect a 50-fold increase in coverage from the $800-\mathrm{km}$-wide ground track of WIVERN.

CHALLENGE AND SUMMARY. We expect that the proposed polarization diversity Doppler radar for WIVERN would be able to provide the horizontal component line-of-sight winds with an accuracy of $2 \mathrm{~m} \mathrm{~s}^{-1}, 50-\mathrm{km}$ resolution in the horizontal, and $<1-\mathrm{km}$ resolution in the vertical over an $800-\mathrm{km}$-wide ground track, for clouds having a $20-\mathrm{km}$ along-track extent and a reflectivity exceeding $-20 \mathrm{dBZ}$. Previous studies suggest that line-of-sight winds have $70 \%$ of the value of full vector winds (Horányi et al. 2015a) and that "sensitive" areas where observations are needed to improve forecasts are often cloudy (McNally 2002). Preparatory mission studies confirm that any artifacts associated with the polarization diversity technique should be rare and can easily be identified and rejected. Recent radar observations from aircraft suggest that ground clutter may introduce a bias into winds being measured below $1 \mathrm{~km}$ over the ocean and $2 \mathrm{~km}$ over the land, but more studies are needed to establish their magnitude and frequency of occurrence; knowledge of these boundary layer winds may be less crucial for 24or 48-h forecasts. Analysis, using the global climatology of cloud echoes obtained from CloudSat, indicates that the number of winds suitable for assimilation into operational weather forecasts should be comparable with the currently available aircraft winds and have similar error characteristics and so should have a significant impact in reducing forecast errors. At present there is a lack of wind observations between 400 and $700 \mathrm{hPa}$; analysis suggests that WIVERN should not suffer from this midlevel gap in coverage. Recent ground-based polarization radar observations indicate that ghost echoes lead to increased random errors of the wind estimates but should be rare and can be identified and flagged, and that biases in wind estimates due to reflectivity gradients in the presence of wind shear can also be identified and should be $<1 \mathrm{~m} \mathrm{~s}^{-1}$. Further airborne and ground-based studies are needed to confirm these results and to obtain a more precise estimate of the occurrence of degraded winds due to nonuniform beam filling, the extent of the blind zone over the ocean, and different land surfaces. It should be possible to identify areas of significant convection by the variability of the line-of-sight winds on the kilometer scale; such regions will not be suitable for assimilation into global forecast models but should provide statistical characteristics of convective motions. The WIVERN configuration with a 800-km-wide ground track would use a similar transmitter to the one that has been operating well above expectations over the last decade on CloudSat, and would rely on well-established polarization diversity techniques for deriving Doppler velocities and a 94GHz antenna, covering a $2.9 \mathrm{~m} \times 1.8 \mathrm{~m}$ grid, comparable in size to the antenna developed in a recent ESA study.

ACKNOWLEDGMENTS. We thank the National Research Council of Canada Convair Aircraft flight crew for conducting the project flights, Cuong Nguyen for data processing, and Andrew Pazmany of ProSensing for the implementation of the PDPP mode on the NRC Airborne W-band Radar. We acknowledge access to the Chilbolton Facility for Atmospheric and Radio Research funded by the Natural Environment Research Council in the United Kingdom. The work performed by ST was carried out at Jet Propulsion Laboratory, California Institute of Technology, under a contract with the National Aeronautics and Space Administration. Support from the CloudSat Project, Global Precipitation Measurement mission program, and NASA Weather Focus Area are gratefully acknowledged. We also benefited from support by ESA Contracts 4000113508 ("Dual Polarization 94GHz antenna for Spaceborne Doppler Radar") and 4000114108 ("Doppler Wind Radar Demonstrator") and CEOI-UKSA Contract RP10G0327E13. 
REFERENCES

Anderson, N. F., C. A. Grainger, and J. L. Smith, 2005: Characteristics of strong updrafts in precipitation systems over the central tropical Pacific Ocean and in the Amazon. J. Appl. Meteor., 44, 731-738, https:// doi.org/10.1175/JAM2231.1.

Baker, W. E., and Coauthors, 2014: Lidar-measured wind profiles: The missing link in the global observing systems. Bull. Amer. Meteor. Soc., 95, 543-564, https:// doi.org/10.1175/BAMS-D-12-00164.1.

Battaglia, A., and P. Kollias, 2015a: Error analysis of a conceptual cloud Doppler stereoradar with polarization diversity for better understanding space applications. J. Atmos. Oceanic Technol., 32, 1298-1319, https://doi.org/10.1175/JTECH-D-14-00015.1.

— and — , 2015b: Using ice clouds for mitigating the EarthCARE Doppler radar mispointing. IEEE Trans. Geosci. Remote Sens., 53, 2079-2085, https:// doi.org/10.1109/TGRS.2014.2353219.

_-, M. O. Ajewole, and C. Simmer, 2007: Evaluation of radar multiple scattering effects in Cloudsat configuration. Atmos. Chem. Phys., 7, 1719-1730, https:// doi.org/10.5194/acp-7-1719-2007.

— , S. Tanelli, S. Kobayashi, D. Zrnić, R. J. Hogan, and C. Simmer, 2010: Multiple-scattering in radar systems: A review. J. Quant. Spectrosc. Radiat. Transfer, 111, 917-947, https://doi.org/10.1016/j .jqsrt.2009.11.024.

_-, T. Augustynek, S. Tanelli, and P. Kollias, 2011: Multiple scattering identification in spaceborne W-band radar measurements of deep convective cores. J. Geophys. Res., 116, D19201, https://doi .org/10.1029/2011JD016142.

— , S. Tanelli, and P. Kollias, 2013: Polarization diversity for millimeter space-borne Doppler radars: An answer for observing deep convection? J. Atmos. Oceanic Technol., 30, 2768-2787, https://doi.org/10.1175 /JTECH-D-13-00085.1.

—, S. Wolde, L. Pio D’Adderio, C. Nguyen, F. Fois, A. J. Illingworth, and R. Midthassel, 2017: Characterization of surface radar cross sections at W-band at slant angles. IEEE Trans. Geosci. Remote Sens., 55, $3846-$ 3859, https://doi.org/10.1109/TGRS.2017.2682423.

Berg, W., T. L'Ecuyer, and J. M. Haynes, 2010: The distribution of rainfall over oceans from spaceborne radars. J. Appl. Meteor. Climatol., 49, 535-543, https:// doi.org/10.1175/2009JAMC2330.1.

Cardinali, C., 2009: Monitoring the observation impact on the short-range forecast. Quart. J. Roy. Meteor. Soc., 135, 239-250, https://doi.org/10.1002/qj.366.

Forsythe, M., and R. Saunders, 2008: AMV errors: A new approach in NWP. Proc. Ninth Int. Wind Workshop,
Annapolis, MD, EUMETSAT, www.eumetsat .int $/$ website $/ \mathrm{wcm} / \mathrm{idc} / \mathrm{idcplg}$ ? IdcService $=$ GET _FILE\&dDocName=PDF_CONF_P51_S5_22 _FORSYTHE_V\&RevisionSelectionMethod=Latest Released\&Rendition $=$ Web.

GCOS, 2006: Systematic observation requirements for satellite-based products for climate. WMO Rep. GCOS-107 (WMO/TD No. 1338), 90 pp., https:// library.wmo.int/opac/doc_num.php?explnum _id $=3813$.

_, 2017: 22nd Session of the GCOS/WCRP Atmospheric Observational Panel for Climate. WMO Rep. GCOS-207 (WCRP-7/2017), 44 pp., www .wcrp-climate.org/WCRP-publications/2017/Report -Exeter-AOPC-22_final.pdf.

Haynes, J. M., T. S. L'Ecuyer, G. L. Stephens, S. D. Miller, C. Mitrescu, N. B. Wood, and S. Tanelli, 2009: Rainfall retrieval over the ocean with spaceborne W-band radar. J. Geophys. Res., 114, D00A22, https://doi .org/10.1029/2008JD009973.

Horányi, A., C. Cardinali, M. Rennie, and L. Isaksen, 2015a: The assimilation of horizontal line-of-sight wind information into the ECMWF data assimilation and forecasting system. Part I: The assessment of wind impact. Quart. J. Roy. Meteor. Soc., 141, 1223-1232, https://doi.org/10.1002/qj.2430.

,,--- , and,$- 2015 \mathrm{~b}$ : The assimilation of horizontal line-of-sight wind information into the ECMWF data assimilation and forecasting system. Part II: The impact of degraded wind observations. Quart. J. Roy. Meteor. Soc., 141, 1233-1243, https:// doi.org/10.1002/qj.2551.

Illingworth, A. J., and Coauthors, 2015: The EarthCARE satellite: The next step forward in global measurements of clouds, aerosols, precipitation, and radiation. Bull. Amer. Meteor. Soc., 96, 1311-1332, https:// doi.org/10.1175/BAMS-D-12-00227.1.

Janisková, M., 2015: Assimilation of cloud information from space-borne radar and lidar: Experimental study using a $1 \mathrm{D}+4 \mathrm{D}-$ Var technique. Quart. J. Roy. Meteor. Soc., 141, 2708-2725, https://doi.org/10.1002 /qj.2558.

—, P. Lopez, and P. Bauer, 2012: Experimental 1D + 4D-Var assimilation of CloudSat observations. Quart. J. Roy. Meteor. Soc., 138, 1196-1220, https:// doi.org/10.1002/qj.988.

Kollias, P., S. Tanelli, A. Battaglia, and A. Tatarevic, 2014: Evaluation of EarthCARE cloud profiling radar Doppler velocity measurements in particle sedimentation regimes. J. Atmos. Oceanic Technol., 31, 366386, https://doi.org/10.1175/JTECH-D-11-00202.1.

Langland, R., and N. L. Baker, 2004: Estimation of observation impact using the NRL atmospheric variational 
data assimilation adjoint system. Tellus, 56A, 189-201, https://doi.org/10.3402/tellusa.v56i3.14413.

L'Ecuyer, T. S., and G. L. Stephens, 2002: An estimationbased precipitation retrieval algorithm for attenuating radars. J. Appl. Meteor., 41, 272-285, https://doi .org/10.1175/1520-0450(2002)041<0272:AEBPRA $>2.0 . \mathrm{CO} ; 2$

Lhermitte, R., 1990: Attenuation and scattering of millimeter wavelength radiation by clouds and precipitation. J. Atmos. Oceanic Technol., 7, 464-479, https:// doi.org/10.1175/1520-0426(1990)007<0464:AASO $\mathrm{MW}>2.0 . \mathrm{CO} ; 2$.

Li, J.-L., and Coauthors, 2012: An observationally based evaluation of cloud ice water in CMIP3 and CMIP5 GCMs and contemporary reanalyses using contemporary satellite data. J. Geophys. Res., 117, D16105, https://doi.org/10.1029/2012JD017640.

Liu, G., 2008: Deriving snow cloud characteristics from CloudSat observations. J. Geophys. Res., 113, D00A09, https://doi.org/10.1029/2007JD009766.

Liu, Z.-Q., and F. Rabier, 2002: The interaction between model resolution, observation resolution, and observation density in data assimilation: A one-dimensional study. Quart. J. Roy. Meteor. Soc., 128, 1367-1386, https://doi.org/10.1256/003590002320373337.

McNally, A. P., 2002: A note on the occurrence of cloud in meteorologically sensitive areas and the implications for advanced infrared sounders. Quart. J. Roy. Meteor. Soc., 128, 2551-2556, https://doi.org/10.1256/qj.01.206.

Meneghini, R., and T. Kozu, 1990: Spaceborne Weather Radar. Artech House, 199 pp.

Miller, S. D., and G. L. Stephens, 2001: CloudSat instrument requirements as determined from ECMWF forecasts of global cloudiness. J. Geophys. Res., 106, 17713-17733, https://doi.org/10.1029/2000JD900645.

OSCAR, 2016: OSCAR: Observing Systems Capability Analysis and Review Tool. WMO, www.wmo-sat info/oscar/.

Palerme, C., J. E. Kay, C. Genthon, T. L’Ecuyer, N. B. Wood, and C. Claud, 2014: How much snow falls on the Antarctic ice sheet? Cryosphere, 8, 1577-1587, https://doi.org/10.5194/tc-8-1577-2014.

Pazmany, A. J., and Coauthors, 1999: Polarization diversity pulse-pair technique for millimeter-wave Doppler radar measurements of severe storm features. J. Atmos. Oceanic Technol., 16, 1900-1910, https://doi.org/10.1175/1520-0426(1999)016<1900 :PDPPTF>2.0.CO;2.

Salonen, K., J. Cotton, N. Bormann, and M. Forsythe, 2015: Characterizing AMV height-assignment error by comparing best-fit pressure statistics from the Met Office and ECMWF data assimilation systems. J. Appl. Meteor. Climatol., 54, 225-242, https://doi .org/10.1175/JAMC-D-14-0025.1.

Schutgens, N. A., 2008: Simulated Doppler radar observations of inhomogeneous clouds. J. Atmos. Oceanic Technol., 25, 26-42, https://doi .org/10.1175/2007JTECHA956.1.

Skolnik, M. I., 1981: Introduction to Radar Systems. McGraw-Hill, 579 pp.

Stephens, G. L., and Coauthors, 2008: CloudSat mission: Performance and early science after the first year of operation. J. Geophys. Res., 113, D009982, https://doi .org/10.1029/2008JD009982.

Stoffelen, A., and Coauthors, 2005: The Atmospheric Dynamics Mission for global wind measurement. Bull. Amer. Meteor. Soc., 86, 73-87, https://doi .org/10.1175/BAMS-86-1-73.

Sy, O. O., S. Tanelli, N. Takahashi. Y. Ohno, H. Horie, and P. Kollias 2014: Simulation of EarthCARE spaceborne Doppler radar products using ground-based and airborne data: Effects of aliasing and nonuniform beamfilling. IEEE Trans. Geosci. Remote Sens., 99, 14631479, https://doi.org/10.1109/TGRS.2013.2251639.

Tanelli, S., E. Im, S. L. Durden, L. Facheris, and D. Giuli, 2002: The effects of nonuniform beam filling on vertical rainfall velocity measurements with a spaceborne Doppler radar. J. Atmos. Oceanic Technol., 19, 1019-1034, https://doi.org/10.1175/1520 -0426(2002)019<1019:TEONBF>2.0.CO;2.

—, S.L. Durden, E. Im, K.S. Pak, D. G. Reinke, P. Partain, J.M. Haynes, and R. T. Marchand, 2008: CloudSat's cloud profiling radar after two years in orbit: Performance, calibration, and processing. IEEE Trans. Geosci. Remote Sens., 46, 3560-3573, https:// doi.org/10.1109/TGRS.2008.2002030.

Wolde, M., and G. Vali, 2001: Polarimetric signatures from ice crystals observed at $95 \mathrm{GHz}$ in winter clouds. Part I: Dependence on crystal form. J. Atmos. Sci., 58, 828-841, https://doi.org/10.1175/1520 -0469 (2001)058<0828:PSFICO>2.0.CO;2.

Zhang, W., 2016: The vision of space-based component of WMO Integrated Global Observing Systems (WIGOS) in 2040-Anticipating requirements and new space technologies. 2016 EUMETSAT Meteorological Satellite Conf., Darmstadt, Germany, EUMETSAT, www.eumetsat.int/website/wcm/idc /idcplg? IdcService $=$ GET_FILE $\&$ dDocName $=$ ZIP _CONF_2016_PRES_S1_ORAL\&RevisionSelection Method=LatestReleased\&Rendition=Web. 


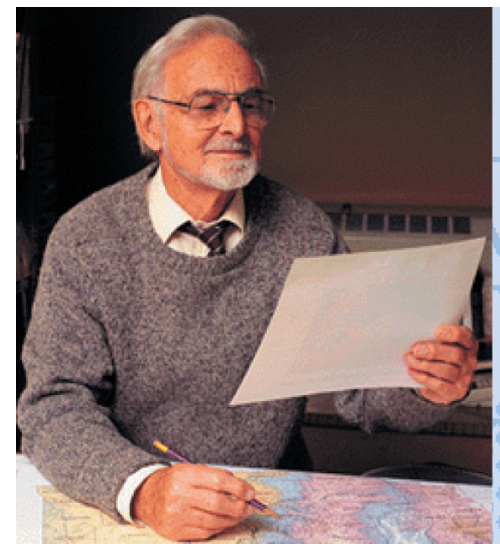

A Half Century of Progress in Meteorology:

A Tribute to Richard Reed

\section{edited by Richard H. Johnson and Robert A. Houze Jr.}

with selections by: Lance F. Bosart Robert W. Burpee Anthony Hollingsworth James R. Holton Brian J. Hoskins Richard S. Lindzen John S. Perry Erik A. Rasmussen Adrian Simmons Pedro Viterbo

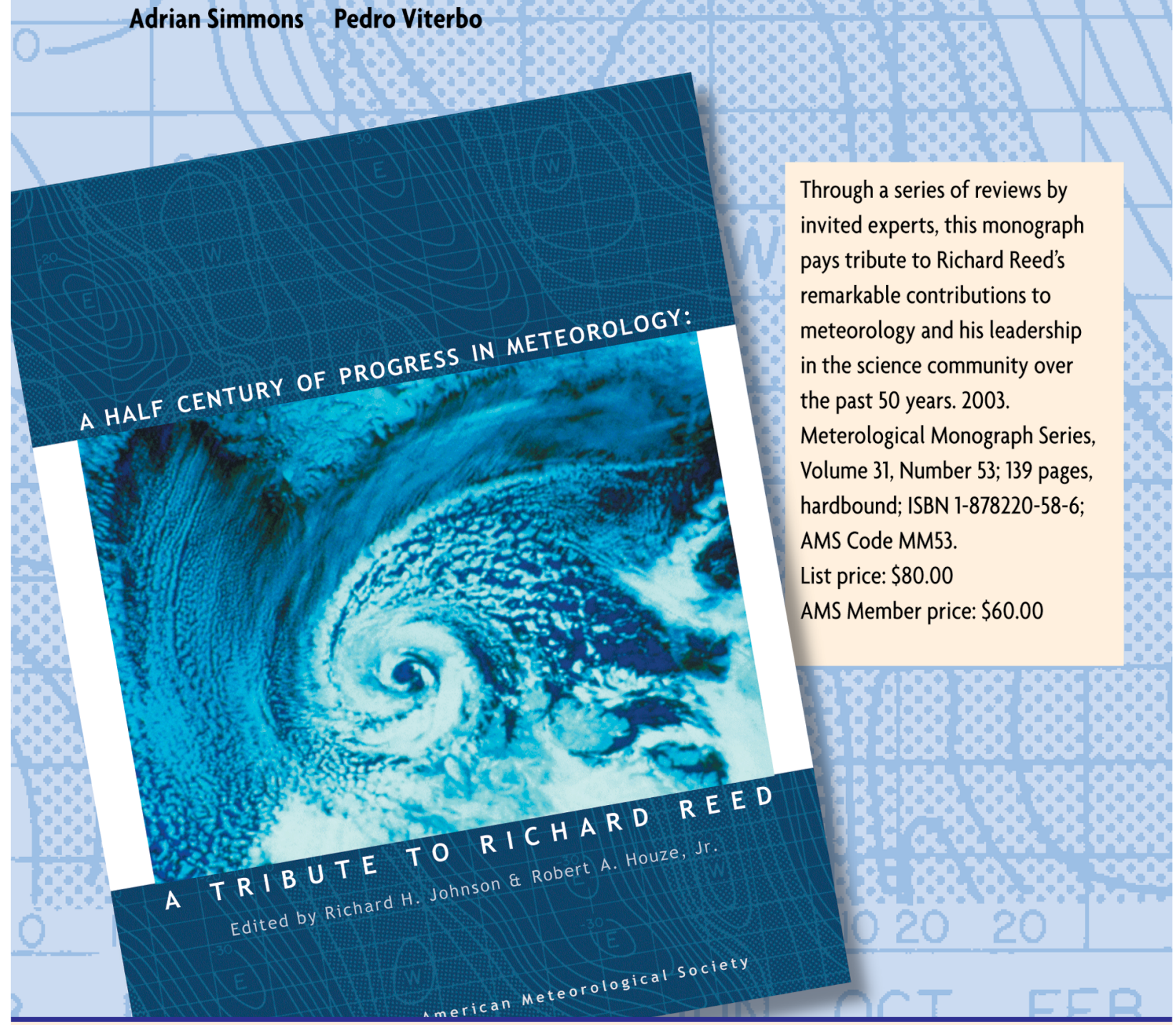

Order Online from bookstore.ametsoc.org 